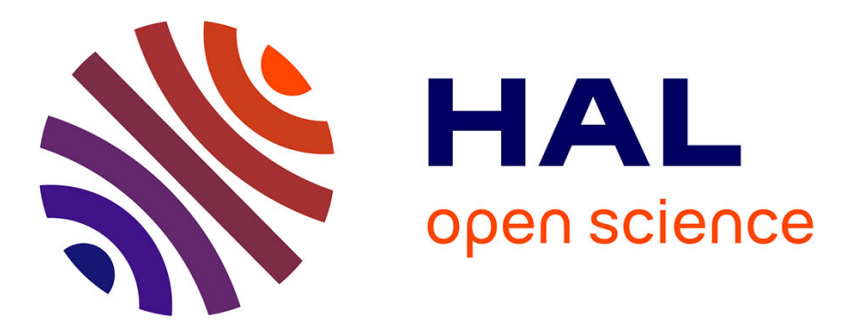

\title{
Hidden Isomer of Trifluoroacetylacetone Revealed by Matrix Isolation Infrared and Raman Spectroscopy
} Alejandro Gutiérrez-Quintanilla, Rasa Platakyte, Michèle Chevalier, Claudine Crépin, Justinas Ceponkus

\section{- To cite this version:}

Alejandro Gutiérrez-Quintanilla, Rasa Platakyte, Michèle Chevalier, Claudine Crépin, Justinas Ceponkus. Hidden Isomer of Trifluoroacetylacetone Revealed by Matrix Isolation Infrared and Raman Spectroscopy. Journal of Physical Chemistry A, 2021, 125 (11), pp.2249-2266. 10.1021/acs.jpca.0c10945 . hal-03189914

\section{HAL Id: hal-03189914 https://hal.science/hal-03189914}

Submitted on 10 Aug 2021

HAL is a multi-disciplinary open access archive for the deposit and dissemination of scientific research documents, whether they are published or not. The documents may come from teaching and research institutions in France or abroad, or from public or private research centers.
L'archive ouverte pluridisciplinaire HAL, est destinée au dépôt et à la diffusion de documents scientifiques de niveau recherche, publiés ou non, émanant des établissements d'enseignement et de recherche français ou étrangers, des laboratoires publics ou privés. 


\title{
Hidden Isomer of Trifluoroacetylacetone Revealed by Matrix Isolation Infrared and Raman Spectroscopy
}

\author{
Alejandro Gutiérrez-Quintanilla, ${ }^{a, b+}$ Rasa Platakyte, ${ }^{c}$ Michèle Chevalier, ${ }^{a}$ Claudine Crépin, ${ }^{* a}$ \\ Justinas Ceponkus*c \\ a'Université Paris-Saclay, CNRS, Institut des Sciences Moléculaires d'Orsay, 91405, Orsay, France. \\ b Instituto Superior de Tecnologías y Ciencias Aplicadas (InSTEC), Universidad de La Habana. Ave. Salvador \\ Allende No. 1110, Quinta de los Molinos, La Habana 10400, Cuba. \\ 'Institute of Chemical Physics, Vilnius University, Sauletekio av. 9, L-10222 Vilnius, Lithuania. \\ † Present address: Aix-Marseille Université, Laboratoire PIIM, Team ASTRO, Service 252, Saint Jérôme, \\ Ave. Escadrille Normandie Niemen, 13013 Marseille, France.
}

*Corresponding authors: claudine.crepin-gilbert@universite-paris-saclay.fr; justinas.ceponkus@ff.vu.lt

\begin{abstract}
Enol forms of trifluoroacetylacetone isolated in molecular and rare gas matrices were studied using infrared and Raman spectroscopy. Additionally, calculations using DFT B3LYP and M06-2X as well as MP2 methods were performed in order to investigate the possibility of coexistence of more than one stable enol form isomer of trifluoroacetylacetone (TFacac). Calculations predict that both stable enol isomers of trifluoroacetylacetone: 1,1,1-trifluoro-4-hydroxy-3-penten-2-one (1) and 5,5,5trifluoro-4-hydroxy-3-penten-2-one (2) could coexist, especially in matrices where room temperature population is frozen, $\mathbf{1}$ being the most stable one. Raman and infrared spectra of trifluoroacetylacetone isolated in nitrogen $\left(\mathrm{N}_{2}\right)$ and carbon monoxide (CO) matrices exhibit clear absorption bands which cannot be attributed to this single isomer. Their relative band positions and intensity profiles match well with the theoretical calculations of 2 . This allows us to confirm that in $\mathrm{N}_{2}$ and $\mathrm{CO}$ matrices both isomers exist in similar amounts. Careful examination of the spectra of TFacac in argon, xenon, neon, normal and para-hydrogen ( $\mathrm{Ar}, \mathrm{Xe}, \mathrm{Ne}, n \mathrm{H}_{2}$ and $p \mathrm{H}_{2}$ respectively) matrices revealed that both isomers coexist in all the explored matrices whereas $\mathbf{2}$ was not considered in the previous spectroscopic works. The amount of the second isomer (2) in the as-deposited samples depends on the host. The analysis of TFacac spectra in the different hosts and under various experimental conditions allows the vibrational characterization of both chelated isomers. The comparison with theoretical predictions is also investigated.
\end{abstract}




\section{Introduction}

Molecular systems possessing internal hydrogen bonds draw close scientific attention, as understanding of the properties of this type of interaction is of crucial importance. Good candidates for the studies of internal hydrogen bonding are the small and medium size molecules, because it is possible to easily handle them during experiments and perform high level quantum chemistry calculations in reasonable amounts of time. The molecules possessing a pseudo ring structure where hydrogen bond "closes" this ring form a peculiar class of molecules where properties of hydrogen bond ( $\mathrm{H}$-bond) are strongly dependent on the delocalized $\pi$ type electronic structure of the molecule. Such type of hydrogen bonding is often called Resonance Assisted Hydrogen Bonding (RAHB). ${ }^{1,2}$ The smallest members of these molecular families are malonaldehyde and acetylacetone (acac), with symmetric substituents linked to the pseudo ring and widely investigated in previous matrix works, ${ }^{3-8}$ and the asymmetric acetylacetaldehyde. ${ }^{9}$ This type of molecules can exist in two tautomeric forms, namely enol and keto, the enol form being the most stable one due to the strong internal hydrogen bond. $^{7}$ These molecules in enolic configuration possess double well potential function for the proton transfer from one oxygen to the other (Figure 1a).

The halogenated derivative of acetylacetone 1,1,1-trifluoroacetylacetone (noted hereafter TFacac) presents an interesting case of the acetylacetone derivatives. Due to the modification, when all fluorine atoms are localized on one side of the molecule, the pseudo $C_{2 v}$ symmetry of acac is broken. Consequently, the hydrogen transfer potential function becomes an asymmetric one, since it is more probable for the hydrogen atom to be localized in one of the two sides (see Figure 1b). This results in the possibility of coexistence of two enolic forms having different structure and stability: one isomer 1,1,1-trifluoro-4-hydroxy-3-penten-2-one (1) is the structure where perfluoromethyl $\left(\mathrm{CF}_{3}\right)$ group is on the same side of the molecule as $-\mathrm{C}=\mathrm{O}$ group and another isomer is 5,5,5-trifluoro-4-hydroxy-3penten-2-one (2) with $\mathrm{CF}_{3}$ group on the same side of the molecule as $-\mathrm{C}-\mathrm{O}-\mathrm{H}$ group. As shown in Figure $1 \mathrm{~b}$, these structures are those of the chelated enol forms of $\mathbf{1}$ and $\mathbf{2}$ which will be noted as $\mathrm{CCC}(\mathrm{CO})$ and $\mathrm{CCC}(\mathrm{OH})$ respectively in this paper. The " $\mathrm{CCC}$ " notation is taken from previous works on $\beta$-dicarbonyl molecules where it depicts the chelated enol conformer with three "Cis" arrangements in the $\mathrm{C}-\mathrm{C}-\mathrm{C}-\mathrm{O}-\mathrm{H}$ chain of the molecule skeleton. ${ }^{5,10,11}$ The other enolic structures of TFacac are shown in the Supporting Information file (SI), Figure S1, together with that of the keto isomer.

There are several theoretical studies on the structure and energy differences between TFacac isomers using very different levels of theory. ${ }^{12-15}$ All these papers agree that $\mathrm{CCC}(\mathrm{CO})$ structure is the most stable one (a global minimum), and $\mathrm{CCC}(\mathrm{OH})$ is a stable but higher energy isomer. However, the calculated energy difference between these two isomers is very different at various levels of theory. The lowest calculated energy difference is $0.7 \mathrm{~kJ} / \mathrm{mol}$ using MP2/6-31++G(d, p), while MP2/6$311++\mathrm{G}(\mathrm{d}, \mathrm{p})$ predicts $2.2 \mathrm{~kJ} / \mathrm{mol}$ energy difference. ${ }^{14}$ The highest calculated energy difference $7.15 \mathrm{~kJ} / \mathrm{mol}$ is obtained using B3LYP/6-311++G** level of theory..$^{13}$ Having in mind that calculation accuracy is heavily dependent on the system under study and the method used, calculations accuracy can be in the range of 2-14 kJ/mol. ${ }^{16}$ Thus available calculated data, having in mind error bars, can suggest two scenarios: (i) both isomers coexist with similar amounts (at lower energy difference limit) at room temperature; or (ii) only one most stable $\mathrm{CCC}(\mathrm{CO})$ isomer exists if the case of high calculated energy difference is correct. 


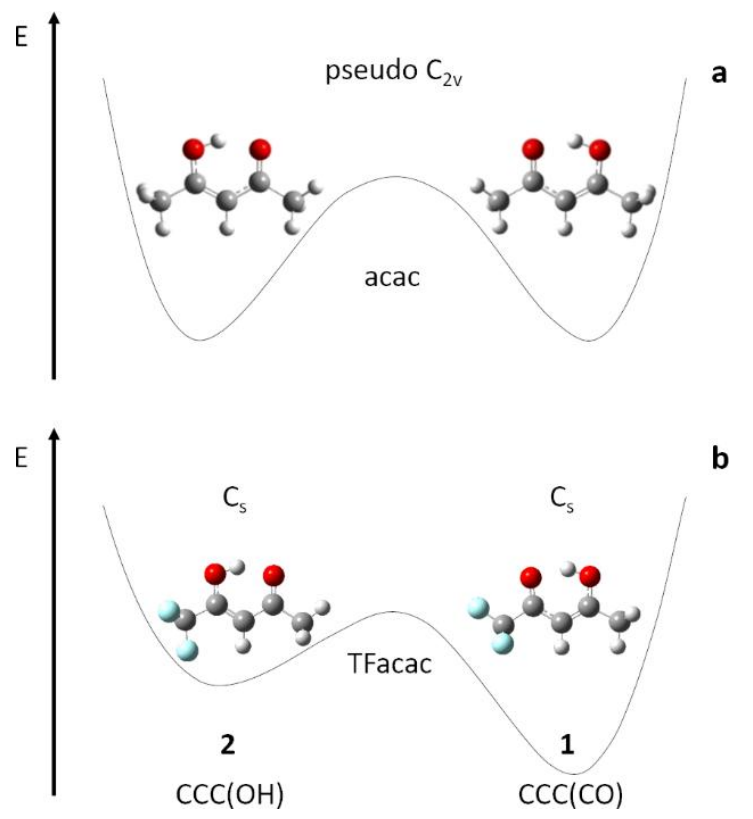

Figure 1: Potential functions (schematic) of hydrogen tunneling for (a) acetylacetone - acac - and (b) trifluoroacetylacetone - TFacac -. Fluorine atoms are represented in light blue. The chelated enol forms of $\mathbf{1}$ and $\mathbf{2}$ isomers of TFacac are shown in panel $\mathbf{b}$ and labelled CCC(CO) and CCC(OH) respectively. The labels indicate cis conformation in respect of rotation around three internal bonds in the $\mathrm{O}=\mathrm{C}-\mathrm{C}=\mathrm{C}-\mathrm{O}-\mathrm{H}$ chain, and $\mathrm{OH}$ or $\mathrm{CO}$ group in the brackets indicating on which side of the molecule $\mathrm{CF}_{3}$ group resides.

There is a number of experimental studies of TFacac in different states: gas, liquid and isolated in cryogenic matrices using different experimental approaches: electron diffraction, NMR, microwave, infrared and Raman spectroscopies. One of the first experimental attempts to define the structure of TFacac was made using electron diffraction. ${ }^{17}$ The authors presumed the $\mathrm{C}_{2 \mathrm{v}}$ structure of acac molecule and were applying the same approach to TFacac molecule, expecting hydrogen atom in the middle between $\mathrm{O} \cdots \mathrm{H} \cdots \mathrm{O}$ bond. This finding is in contradiction with newest theoretical calculations agreeing that based on the non-zero energy difference between the isomers the system has an asymmetrical double well potential for the hydrogen transfer from one oxygen to another.

Another attempt to establish the structure of TFacac was NMR experiments in different solutions. ${ }^{18}$ The possibility of the existence of two energetically different isomers was concluded from the data of NMR chemical shifts. NMR results appeared to be very weakly dependent on the solution nature. They allow to conclude that $\mathrm{CCC}(\mathrm{CO})$ isomer is more stable than $\mathrm{CCC}(\mathrm{OH})$ and both isomers coexist in room temperature solutions. The estimated ratio $\mathrm{R}_{21}=\mathrm{CCC}(\mathrm{OH}) / \mathrm{CCC}(\mathrm{CO})=0.4$ based on Boltzmann distribution gives $2.27 \mathrm{~kJ} / \mathrm{mol}$ energy difference between two isomers which is in perfect agreement with high level $a b$ initio calculations: $\sim 2.2 \mathrm{~kJ} / \mathrm{mol}$ using MP2/6-311++G(d,p). ${ }^{14,19}$

Vibrational spectroscopy is one of the best tools to examine such type of problems, as vibrational frequencies of particular vibrational modes should be very sensitive to the strength of the hydrogen bond, and hydrogen atom position in the molecule. First extensive attempts to characterize acac and its fluorinated derivatives based on infrared and Raman spectroscopy ${ }^{20}$ in solution state allowed to establish that all acac derivatives possess double well potential for the proton transfer and hydrogen is localized closer to one of the oxygen atoms when the system is in the potential minima. However, these first works have not addressed the problem of possible existence of two different enol isomers 
as in the case of TFacac. Other works re-examined the infrared and Raman spectra of TFacac placing particular attention to the investigation of this molecule. ${ }^{13,21}$ Raissi and coworkers ${ }^{13}$ started with extensive theoretical investigation of TFacac structure. Their calculations at different levels led to the energy difference between stable isomers in the range between 4 to $7 \mathrm{~kJ} / \mathrm{mol}$. Assuming average energy difference between isomers of $5 \mathrm{~kJ} / \mathrm{mol}$, authors directly discarded the possibility to experimentally observe the second less stable isomer and performed vibrational analysis assuming the presence of only one isomer. In a parallel study Zahedi-Tabrizi et al. ${ }^{21}$ performed theoretical calculations and vibrational study of TFacac in gas phase and solution. Comparing energies of the two isomers and their calculated spectra with the experimental one, authors concluded "2TFAA (i.e. $\mathrm{CCC}(\mathrm{CO})$ with the present notations) is the only isomer in the sample or at least the dominant species" and continued further spectral bands assignment presuming the existence of only one isomer. A detailed examination of experimental and calculated spectra of both isomers revealed that there are not so many spectral bands which would be good candidates for solid establishment of either case. Most of the bands from both isomers are almost at the same vibrational frequencies making them very difficult to discriminate in the experimental vibrational spectra. Matrix isolation technique, on the other hand, facilitates solving this problem. Typically, vibrational bands of matrix isolated molecules have bandwidth of the order of several $\mathrm{cm}^{-1}$ or even less, while bands of liquid samples present as broad features usually spanning more than $10 \mathrm{~cm}^{-1}$. The first matrix isolation study of TFacac, performed in argon matrices, ${ }^{22}$ was highly focused on the identification of nonchelated and less stable isomers produced after sample UV irradiation. The authors concluded that they observe only one stable isomer of TFacac in the Ar samples directly after deposition. However, they also state that there are several bands in their experimental spectra which cannot be easily assigned to the only one isomer. The authors tentatively attributed these bands to matrix induced effects or/and Fermi resonances without further discussion.

One of the latest attempts to characterize the structure of the TFacac chelated enol form was performed by Favero et al. by means of microwave experiments aided with ab initio calculations. ${ }^{19}$ The rotational spectra are very informative regarding geometry of the species under study and can provide detailed structural information when used together with high level computational data. Based on experimental data the authors confirmed $\mathrm{C}_{\mathrm{s}}$ structure of the enol isomer of TFacac, with hydrogen localized closer to one of the oxygen atoms. Internal rotation of the $\mathrm{CH}_{3}$ and $\mathrm{CF}_{3}$ groups was also confirmed from experimental data. The attempts to assign rotational spectra to the possible geometrical structures of TFacac led authors to the conclusion that only the most stable isomer $\mathrm{CCC}(\mathrm{CO})$ is observable in the experiment. Their MP2 calculated energy difference at $176 \mathrm{~cm}^{-1}(2.1$ $\mathrm{kJ} / \mathrm{mol}$ ) suggested the possibility that both isomers could coexist. The authors attributed the failure to observe the second isomer to possible fast relaxation via proton tunneling to the most stable isomer in their experimental conditions, using pulsed-supersonic-jet technique.

A recent study lead by some of the present authors on complex formation between acac (as well as its fluorinated derivatives) and water ${ }^{23}$ has drawn closer attention to the problem of the coexistence of two stable enol isomers of TFacac isolated in low temperature matrices. The results showed that both possible TFacac enolic isomers are observed in nitrogen matrix, but not in argon. A few IR bands were assigned to $\mathrm{CCC}(\mathrm{OH})$ in $\mathrm{N}_{2}$ matrix. These assignments were strongly reinforced by the study of complexes between TFacac and $\mathrm{H}_{2} \mathrm{O}$ in Ar and $\mathrm{N}_{2}$ matrices, highlighting the stabilization of $\mathrm{CCC}(\mathrm{OH})$ in Ar when complexed with water. However, only two IR bands were clearly assigned to vibrational modes of $\mathrm{CCC}(\mathrm{OH})$, the others showing either a very low intensity or a discrepancy with theoretical values. 
As it can be seen in the references above, the infrared absorption spectra of TFacac is much more complicated than its parent molecule acac both in liquid state and even in low temperature matrices, and still lacks a more complete assignment. The recent attempts to use the softest and least perturbing environment - para-hydrogen $\left(\mathrm{pH}_{2}\right)$ matrix ${ }^{24}$ confirm the previous observations. The infrared spectra of TFacac in $\mathrm{pH}_{2}$ shows very complicated band structure and for some vibrational modes the assignment of the bands is far from being straightforward.

The problem of experimental data interpretation is heavily affected by the complications in theoretical calculations. Comparison between calculated spectra available in the literature using different methods ${ }^{13,21-24}$ revealed significant discrepancies for several vibrational modes, making the assignment of the experimental spectra very complicated and somewhat calculation method dependent.

All the observations mentioned above clearly demonstrate that the interpretation of the experimental and theoretical data is far from trivial. The possibility of the coexistence of the two TFacac isomers is possible and in order to solve this problem a more complete and systematic vibrational study involving both experiments and theory is still needed. In order to re-evaluate the possibility of the coexistence of both stable enol isomers of TFacac we have performed Raman spectroscopic studies of TFacac isolated in $\mathrm{N}_{2}, \mathrm{CO}, \mathrm{Ar}$ and $\mathrm{Xe}$ matrices followed by infrared absorption experiments in $\mathrm{N}_{2}, \mathrm{CO}, \mathrm{Ar}, n \mathrm{H}_{2}$ (normal $\mathrm{H}_{2}$ ) and $p \mathrm{H}_{2}$ matrices. In order to address the problems of theoretical calculations, we calculated the structures of isomers and their vibrational spectra using DFT B3LYP-D3, M06-2X and ab initio MP2 approaches. Torsional barriers for $\mathrm{CF}_{3}$ and $\mathrm{CH}_{3}$ groups were also estimated using MP2.

\section{Methods}

\section{A. Theoretical calculations}

The calculations were run using Gaussian 16 (B.01) and 09 (D.01) software versions ${ }^{25,26}$ in the GMPCS cluster (Grappe Massivement Parallèle de Calcul Scientifique) at Orsay, Université Paris-Saclay, and at the High Performance Computing Center "HPC Sauletekis" in Vilnius University Faculty of Physics. Geometry optimizations for two isomers of trifluoroacetylacetone ( $\mathrm{CCC}(\mathrm{CO})$ and $\mathrm{CCC}(\mathrm{OH})$ ), as well as frequency calculations were performed at the Density Functional Theory (DFT) level of theory with either B3LYP ${ }^{27,28}$ or M06-2X functional ${ }^{29}$ and $6-311++G(3 d f, 3 p d)$ basis set. The M06-2X in particular was chosen because it has been shown that it can produce a better description of vibrational spectra for halogenated molecules than B3LYP, especially for the C-F vibrational modes. ${ }^{30}$ The D3 Grimme's dispersion correction method was also included in the case of the B3LYP functional. ${ }^{31} \mathrm{~A}$ very tight convergence criteria and the -96032 integration grid were used in all calculations. Vibrational frequencies were obtained by means of harmonic approach. Calculations were also performed using second-order Møller-Plesset perturbation theory (MP2) within the frozen core (FC) approximation and with the same basis set $(6-311++\mathrm{G}(3 \mathrm{df}, 3 \mathrm{pd}))$ and tight convergence criteria. Relaxed scans for $\mathrm{CF}_{3}$ and $\mathrm{CH}_{3}$ torsional barriers in each isomer were performed at this same level of theory.

\section{B. Experimental setup}

Three different experimental setups were used in order to get most detailed results. In the first one (in Vilnius, Lithuania), trifluoroacetylacetone (98\%) from Sigma-Aldrich was degassed in the vacuum system by using freeze-pump-thaw cycle and used without further purification. Nitrogen ( $99.999 \%)$, 
argon (99.999 \%), xenon, neon and carbon monoxide (99.995\%) gases from Elme Messer Gaas were used without additional treatment. Sample and matrix gases were mixed in glass vacuum system with their ratios estimated by measuring partial gas pressure. In a typical experiment, $1 \mathrm{mbar}$ of the sample molecule and 500 mbar of the matrix gas were mixed before approximately $20 \mathrm{mmol}$ of gas mixture was deposited in 90 minutes onto a spectral window (cesium iodide) held at $10 \mathrm{~K}$ in a closed cycle He cryostat (Leybold-Heraeus RW2).

Infrared absorption spectra were recorded in the 500-4000 $\mathrm{cm}^{-1}$ range using a Bruker IFS 120 spectrometer at $1 \mathrm{~cm}^{-1}$ resolution, averaging 256 spectra. The background spectra and the sample spectra were measured under the same conditions. Annealing experiments were performed with the samples being heated to $30 \mathrm{~K}$ and cooled back to $12 \mathrm{~K}$ for argon, nitrogen and carbon monoxide matrices. Spectra were recorded at both points to follow temperature and annealing effects on the sample.

Same steps were followed during Raman experiments. The mixture ratio for a typical experiment was 1:100 of TFacac to matrix gas in order to obtain a better signal intensity for Raman scattering. The spectra were registered in 50-5000 $\mathrm{cm}^{-1}$ range with Bruker FT-Raman spectrometer at $4 \mathrm{~cm}^{-1}$ and 1 $\mathrm{cm}^{-1}$ resolution, using a laser excitation at $785 \mathrm{~nm}$. Duration of the deposition was set to about 2-3 hours.

Two different matrix isolation experimental setups were used for IR studies in Orsay, France. The first one was used for argon, nitrogen and neon matrices. Samples were obtained in the same manner as in Vilnius. The second setup was employed for experiments in para-hydrogen matrix. It included two closed cycle helium cryostats, connected by a stainless steel tube. First cryostat was used for the ortho/para-hydrogen conversion process (Air Products, Displex DE202) with $\mathrm{Fe}_{2} \mathrm{O}_{3}$ powder (SigmaAldrich $99 \%$ ) as catalyst, and the other for the sample deposition (ICE: Innovative Cryogenic Engineering, RDK 415D, He Compressor: Sumitomo F-50). In the ortho/para-conversion cryostat, the temperature was raised to $15-17 \mathrm{~K}$ after conversion around $14 \mathrm{~K}$, and $p \mathrm{H}_{2}$ was sent in the tube. $\mathrm{A}$ small reservoir containing the sample was attached to this tube. Two Swagelok microvalves allowed controlling the host gas flux $\left(\mathrm{pH}_{2}\right)$ and the amount of vapor from the sample. The mixture of gases arrived directly in front of the internal diamond window $(2.8 \mathrm{~K})$ fixed to the cold head of the second cryostat. This cryostat was pumped by a turbomolecular pump (Oerlikon, Leybold vacuum, Turbovac $600 \mathrm{C}$, pumping speed for $\mathrm{H}_{2}: 570 \mathrm{I}^{-1} \mathrm{~s}^{-1}$ ), which allowed reaching pressures below $10^{-6}$ mbar at $293 \mathrm{~K}$. The $\mathrm{pH}_{2}$ converter was pumped by a diffusion pump (CIT Alcatel). Few experiments in Ne were performed with this second set-up replacing $\mathrm{H}_{2}$ by Ne before the converter and maintaining the temperature of the conversion cryostat at $60 \mathrm{~K}$ to let a flow of $\mathrm{Ne}$ going through. Only IR spectroscopy was carried out in Orsay. The IR spectra were obtained by means of a FT-IR spectrometer (Nicolet $670 / 870$ or iS50) at a resolution of $0.5 \mathrm{~cm}^{-1}$, averaging 500 to 5000 scans. The limit resolution of $0.125 \mathrm{~cm}^{-1}$ was used to verify that some band structures were not hidden in the previously described spectra.

Some UV irradiation experiments were also conducted in Orsay, using an OPO laser (Continuum Surelite II + OPO (Optical Parametric Oscillator) Horizon system, repetition rate: $10 \mathrm{~Hz}$, pulsewidth: 4 $\mathrm{ns})$, operating in the $220-300 \mathrm{~nm}$ range with less energy than $1 \mathrm{~mJ} /$ pulse. IR spectra were recorded before and after irradiation at a specific excitation wavelength, and several different wavelengths were applied to the same sample.

\section{Theoretical Results}


As mentioned in the "Introduction" section there are several works addressing the energetic stability and geometrical structure of TFacac enol isomers, including the analysis of the intramolecular hydrogen bond. ${ }^{12-15,19,21,22,32}$ In all the aforementioned studies the $\mathrm{CCC}(\mathrm{CO})$ isomer have been found as the most stable enol isomer. According to these results, this isomer is more stable than $\mathrm{CCC}(\mathrm{OH})$ isomer by $\Delta \mathrm{E}_{c c c}=3.4-4.7 \mathrm{~kJ} \cdot \mathrm{mol}^{-1}$ (values obtained using B3LYP/6-31G* and higher basis sets). ${ }^{12-14,22}$ Raissi et al. ${ }^{13}$ analyzed the dependence of $\Delta \mathrm{E}_{\text {ccc }}$ on the basis set size using DFT/B3LYP. They found a positive correlation between $\Delta \mathrm{E}_{\mathrm{ccc}}$ and the basis set size, obtaining a maximum value of $7.7 \mathrm{~kJ}^{\mathrm{mol}}{ }^{-1}$ with $6-311++G^{* *}$ basis set. However, the values previously reported have to be taken with precaution because they seem to be based, at least for $\mathrm{CCC}(\mathrm{CO})$, on a structure that does not correspond to the global minimum.

A closer inspection of previous reports shows that there is a clear discrepancy between the different results regarding the relative configuration of the $\mathrm{CF}_{3}$ group in the $\mathrm{CCC}(\mathrm{CO})$ optimized geometry with respect to the backbone plane of symmetry. In some of these works, the configuration of the $\mathrm{CF}_{3}$ group is not even reported or explicitly discussed. ${ }^{13,14,22}$ Favero et al. ${ }^{19}(\mathrm{MP} 2 / 6-311++\mathrm{G}(\mathrm{d}, \mathrm{p}))$ and Sliznev et al. ${ }^{15}$ (B3LYP/Huzinaga-Dunning) have found a geometry where the $\mathrm{CF}_{3}$ group is close to the eclipsed configuration regarding the $\mathrm{C}=0$ group, but the symmetrical geometry $\left(\mathrm{C}_{\mathrm{s}}\right)$ is not completely reached in either case. In the other reports the geometry of the $\mathrm{CF}_{3}$ group is mainly close to the staggered configuration (also close to $C_{s}$ symmetry). Favero et al. also show the presence of only one minimum at the eclipsed configuration in the potential energy surface (PES) for the internal rotation of the $\mathrm{CF}_{3}$ group. Because of all these discrepancies we decided to revisit these calculations and to perform our own simulations.

Table 1: Geometries of the two chelated enol isomers of TFacac obtained by ab initio MP2 calculations with the $6-311++G(3 d f, 3 p d)$ basis set: main distances $R$ in $\AA$, angles $A$ and dihedral angles $D$ in degrees. Schemes of the molecules obtained with the Chemcraft software. ${ }^{33}$

\begin{tabular}{|c|c|c|c|c|}
\hline \multicolumn{5}{|c|}{ MP2/6-311++G(3df,3pd) } \\
\hline \multicolumn{2}{|l|}{ CO } & \multicolumn{2}{|l|}{$\mathrm{OH}$} & \\
\hline $\mathrm{R}\left(\mathrm{C}_{1}-\mathrm{C}_{5}\right)$ & 1.539 & $\mathrm{R}\left(\mathrm{C}_{1}-\mathrm{C}_{5}\right)$ & 1.500 & \\
\hline$R\left(C_{5}-C_{6}\right)$ & 1.426 & $\mathrm{R}\left(\mathrm{C}_{5}-\mathrm{C}_{6}\right)$ & 1.452 & \\
\hline $\mathrm{R}\left(\mathrm{C}_{5}-\mathrm{O}_{13}\right)$ & 1.237 & $\mathrm{R}\left(\mathrm{C}_{5}-\mathrm{O}_{13}\right)$ & 1.241 & \\
\hline $\mathrm{R}\left(\mathrm{C}_{6}-\mathrm{C}_{8}\right)$ & 1.37 & $\mathrm{R}\left(\mathrm{C}_{6}-\mathrm{C}_{8}\right)$ & 1.357 & \\
\hline $\mathrm{R}\left(\mathrm{C}_{8}-\mathrm{C}_{9}\right)$ & 1.486 & $\mathrm{R}\left(\mathrm{C}_{8}-\mathrm{C}_{9}\right)$ & 1.513 & \\
\hline $\mathrm{R}\left(\mathrm{C}_{8}-\mathrm{O}_{14}\right)$ & 1.321 & $\mathrm{R}\left(\mathrm{C}_{8}-\mathrm{O}_{14}\right)$ & 1.317 & $\mathrm{CCC}(\mathrm{CO})$ - isomer 1 \\
\hline $\mathrm{R}\left(\mathrm{O}_{14}-\mathrm{H}_{15}\right)$ & 0.994 & $\mathrm{R}\left(\mathrm{O}_{14}-\mathrm{H}_{15}\right)$ & 1.002 & \\
\hline $\mathrm{A}\left(\mathrm{O}_{13}-\mathrm{H}_{15}-\mathrm{O}_{14}\right)$ & 149.1 & $\mathrm{~A}\left(\mathrm{O}_{13}-\mathrm{H}_{15}-\mathrm{O}_{14}\right)$ & 149.2 & \\
\hline$A\left(C_{5}-C_{6}-C_{8}\right)$ & 119.5 & $A\left(C_{5}-C_{6}-C_{8}\right)$ & 119.0 & \\
\hline $\mathrm{D}\left(\mathrm{F}_{4}-\mathrm{C}_{1}-\mathrm{C}_{5}-\mathrm{O}_{13}\right)$ & 0 & $\mathrm{D}\left(\mathrm{H}_{4}-\mathrm{C}_{1}-\mathrm{C}_{5}-\mathrm{O}_{13}\right)$ & 0 & \\
\hline $\mathrm{D}\left(\mathrm{H}_{12}-\mathrm{C}_{9}-\mathrm{C}_{8}-\mathrm{O}_{14}\right)$ & 180 & $\mathrm{D}\left(\mathrm{F}_{12}-\mathrm{C}_{9}-\mathrm{C}_{8}-\mathrm{O}_{14}\right)$ & 180 & \\
\hline $\mathrm{D}\left(\mathrm{C}_{5}-\mathrm{O}_{13}-\mathrm{H}_{15}-\mathrm{O}_{14}\right)$ & 0 & $\mathrm{D}\left(\mathrm{C}_{5}-\mathrm{O}_{13}-\mathrm{H}_{15}-\mathrm{O}_{14}\right)$ & 0 & \\
\hline $\mathrm{D}\left(\mathrm{O}_{13}-\mathrm{C}_{5}-\mathrm{C}_{6}-\mathrm{C}_{8}\right)$ & 0 & $\mathrm{D}\left(\mathrm{O}_{13}-\mathrm{C}_{5}-\mathrm{C}_{6}-\mathrm{C}_{8}\right)$ & 0 & d) - isamar \\
\hline $\mathrm{D}\left(\mathrm{C}_{5}-\mathrm{C}_{6}-\mathrm{C}_{8}-\mathrm{O}_{14}\right)$ & 0 & $\mathrm{D}\left(\mathrm{C}_{5}-\mathrm{C}_{6}-\mathrm{C}_{8}-\mathrm{O}_{14}\right)$ & 0 & cc(on) - isomer 2 \\
\hline
\end{tabular}


$\mathrm{CCC}(\mathrm{OH})$ and $\mathrm{CCC}(\mathrm{CO})$ geometries obtained with MP2 ab initio calculations are reported in Table 1. Our MP2 and DFT/M06-2X simulations with 6-311++G(3df,3pd) basis set show a clear $\mathrm{C}_{\mathrm{s}}$ eclipsed symmetry for $\mathrm{CF}_{3}$ in $\mathrm{CCC}(\mathrm{CO})$. However, when B3LYP functional is used the previous symmetry breaks, having the $\mathrm{CF}_{3}$ group rotated by 30 degrees with respect to the eclipsed configuration. Inclusion of Grimme's empirical dispersion corrections only reduce this dihedral angle to 18 degrees. We have concluded that the geometry of the $\mathrm{CCC}(\mathrm{CO})$ isomer is of $\mathrm{C}_{s}$ symmetry (or very close to it). Regarding the geometry of $\mathrm{CCC}(\mathrm{OH})$ isomer we obtain a clear $\mathrm{C}_{\mathrm{s}}$ symmetry with eclipsed $\mathrm{CH}_{3}$ group and staggered $\mathrm{CF}_{3}$ group, even when using B3LYP without dispersion corrections. The complete structural information of both isomers obtained at the different levels of theory can be found in the Supporting Information file (SI), Table S1.

It is worth to notice that we were obliged to decrease the convergence criterion, from "verytight" in B3LYP and M06-2X to "tight" in MP2, because of difficulties obtaining an optimized geometry with the strictest criteria for the $\mathrm{CCC}(\mathrm{CO})$ isomer. In fact, in the last steps of the non-convergent optimization procedure (MP2 "verytight") the maximum displacement is observed in the $\mathrm{O}=\mathrm{C}-\mathrm{C}-\mathrm{F}$ dihedral angle. This could indicate the presence of a very shallow potential or a small barrier for the $\mathrm{CF}_{3}$ group torsional mode, in agreement with the MP2/6-311++G(d,p) PES for the internal rotation of

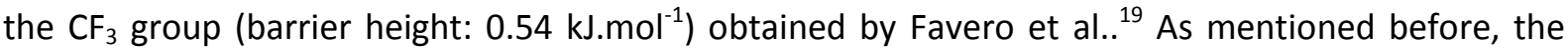
minimum energy geometry obtained in their calculations for the $\mathrm{CCC}(\mathrm{CO})$ isomer does not correspond exactly to the $\mathrm{C}_{\mathrm{s}}$ geometry, the $\mathrm{CF}_{3}$ group is slightly out of plane. We have decided then to calculate the different torsional profiles at the MP2(FC)/ 6-311++G(3df,3pd) level (Figure 2).

The $\mathrm{CF}_{3}$ torsional barrier exhibits an interesting profile (see Figure 2a). First, the barrier height is quite low $\left(0.35 \mathrm{~kJ} \mathrm{~mol}^{-1}\right)$ in agreement with Favero's theoretical result $\left(0.54 \mathrm{~kJ} . \mathrm{mol}^{-1}\right)$. However, the result reported by us is closer to the experimental value $\left(0.37 \mathrm{~kJ} \cdot \mathrm{mol}^{-1}\right)$ obtained by the same authors through a fitting of the FT-MW spectra. The energy of the $\mathrm{CF}_{3}$ torsional mode $\left(\mathrm{TCF}_{3}\right)$ calculated with MP2 is about $0.14 \mathrm{~kJ} \mathrm{~mol}^{-1}$. This value is lower than the torsional barrier height, although still comparable, indicating that we are not in the case of a free internal rotor under the experimental conditions. Nonetheless, caution must be paid to the fact that such small calculated frequencies are not always completely reliable within the frame of harmonic oscillator model. Second, a very small $\left(0.07 \mathrm{~kJ} \mathrm{~mol}^{-1}\right)$ local minimum appears at 60 degrees apart from the eclipsed configuration. This could probably explain the $\mathrm{CF}_{3}$ staggered configurations obtained by some authors at other levels of theory.

We have also performed same kind of calculations for the $\mathrm{CCC}(\mathrm{OH})$ isomer (see Figure $\mathrm{S} 2$ in $\mathrm{SI})$. A similar behavior to the one already described for $\mathrm{CCC}(\mathrm{CO})$ is observed regarding the relative height of both barriers and the placement of the groups in the $\mathrm{C}=\mathrm{O}$ or $\mathrm{C}-\mathrm{OH}$ side. The group placed in the $\mathrm{C}-\mathrm{OH}$ side - $\mathrm{CF}_{3}$ in the current case - has the higher barrier $\left(7.3 \mathrm{~kJ}^{\mathrm{mol}}{ }^{-1}\right)$, while the $\mathrm{CH}_{3}$ in the $\mathrm{C}=0$ presents a noticeable small barrier $\left(2.0 \mathrm{~kJ} \cdot \mathrm{mol}^{-1}\right)$. Contrary to $\mathrm{CCC}(\mathrm{CO})$, no second local minimum was found. 
a

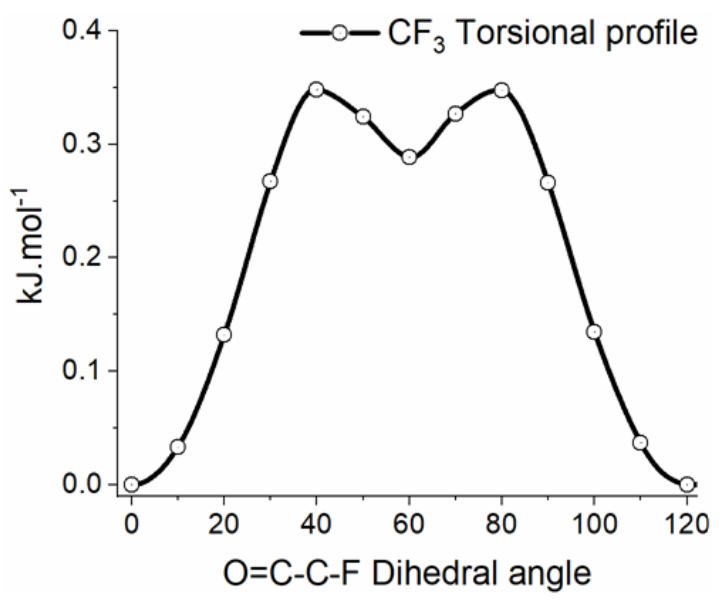

b

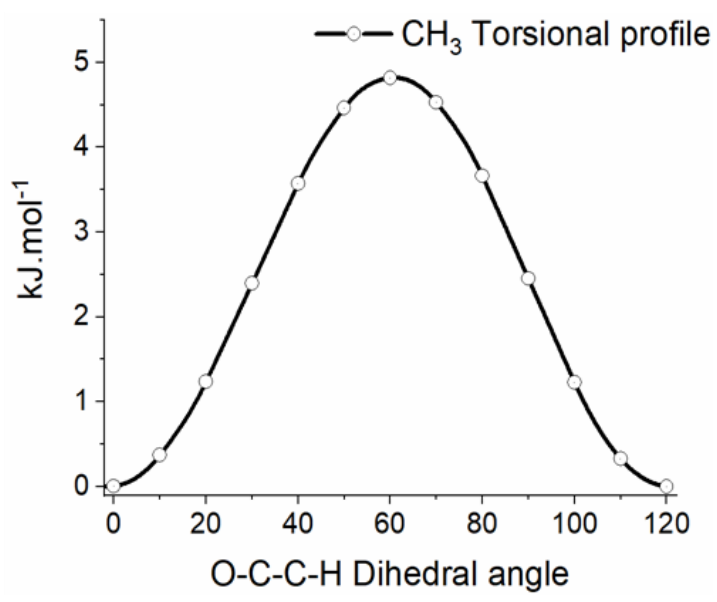

Figure 2 : Relaxed torsional barriers for $(\mathbf{a}) \mathrm{CF}_{3}$ and (b) $\mathrm{CH}_{3}$ groups in the $\mathrm{CCC}(\mathrm{CO})$ tautomer obtained at the MP2(FC)/ 6-311++G(3df,3pd) level of theory. An Akima interpolation spline is used as a guide for the eye.

Regarding the relative energies within the framework of our simulation, we have obtained $\Delta \mathrm{E}_{\mathrm{ccc}}$

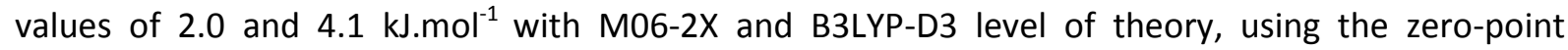
correction. With the MP2 (FC) perturbation method a value of $1.0 \mathrm{~kJ}^{\mathrm{mol}}{ }^{-1}$ is obtained. According to the Boltzmann distribution at $298 \mathrm{~K}$, and assuming the $\triangle \mathrm{E}_{\mathrm{ccc}} \mathrm{MP2}$ value as the closer to the correct absolute value, we obtain populations of $60: 40$ for $\mathrm{CCC}(\mathrm{CO})$ and $\mathrm{CCC}(\mathrm{OH})$ isomers. This ratio is different from the 89:11 previously obtained by some of the present authors using B3LYP. ${ }^{23}$ In both cases the ratio changes to almost 100:0 at less than $10 \mathrm{~K}$. The most important conclusion is that theoretically the amount of $\mathrm{CCC}(\mathrm{OH})$ in equilibrium with $\mathrm{CCC}(\mathrm{CO})$ in the gas phase at room temperature is non negligible.

We have computed the harmonic frequencies for the different normal modes in both CCC isomers by using MP2, B3LYP-D3 and M06-2X methods. The whole set of values is reported in Tables 2 and 3. Most of the modes share a similar description and energetic order in the three theoretical levels. However, some modes do not follow the same trend in the three used methods. The comparison is not made in absolute values between the three methods, instead we compare the position of a specific mode (respect to the adjacent modes) within one method with what is observed in the other two. Clear examples in $\mathrm{CCC}(\mathrm{CO})$ are the $\mathrm{O}-\mathrm{H}$ stretching $\left(\mathrm{V}_{\mathrm{OH}}\right)$ which seems to be "overestimated" in M06-2X, and the asymmetric C-F stretching in the $\mathrm{CF}_{3}$ group ( $\left.\mathrm{V}_{\mathrm{CF} 3}(\mathrm{as})\right)$ which is "underestimated" in B3LYP-D3. The difference between the three methods are more evident in $\mathrm{CCC}(\mathrm{OH})$, mostly because of some M06-2X values like $\mathrm{V}_{\mathrm{OH}}$ (mode 4), $\mathrm{v}_{\mathrm{CF} 3}$ (mode 15), $\delta_{\text {Сн3 }}$ (mode 8) or $\mathrm{Y}_{\mathrm{OH}}$ (mode 20) appearing in a different frequency ordering with respect to MP2 and B3LYP-D3 values. Figures S3 and S4 in SI show the correlations between theoretical frequencies obtained with the three methods. In summary, B3LYP-D3 and MP2 share a similar trend in mode description, while M06-2X tends to underestimate or overestimate some modes (especially $v_{\mathrm{OH}}, v_{\mathrm{CO}} / \mathrm{v}_{\mathrm{C}=\mathrm{C}}$ (as), $\mathrm{v}_{\mathrm{CF} 3}$ (as), $\delta_{\mathrm{OH}}$ and $\mathrm{V}_{\mathrm{OH}}$ ) compared to both aforementioned methods (see notations and numbering in Tables 2 and 3 ). The comparison with the experimental values, which is the real criteria of relevance, will be given later. 
Table 2: Theoretical harmonic frequencies $\left(\mathrm{cm}^{-1}\right)$ with IR intensities $(\mathrm{km} / \mathrm{mol})$ and Raman scattering activities $(\AA / a . m . u)$ in parenthesis at the $M P 2 /, \mathrm{M} 06-2 X /$ and B3LYP-D3/6-311++G(3df,3pd) levels of theory (unscaled) for CCC(CO) isomer. The corresponding assignments are also included.

\begin{tabular}{|c|c|c|c|c|c|c|c|c|c|c|}
\hline \multirow{3}{*}{$\begin{array}{c}\begin{array}{c}\text { Mode } \\
\text { No. }\end{array} \\
1 \\
\end{array}$} & \multicolumn{10}{|c|}{$\operatorname{ccc}(\mathrm{CO})$} \\
\hline & \multicolumn{3}{|c|}{ MP2 } & \multicolumn{3}{|c|}{ M06-2X } & \multicolumn{3}{|c|}{ B3LYP-D3 } & \multirow{2}{*}{$\begin{array}{l}\text { Assignment - simplified description } \\
\mathrm{vC}_{\mathrm{sp} 2} \mathrm{H}\end{array}$} \\
\hline & 3277 & 2 & (54) & 3257 & 2 & $(47)$ & 3238 & 3 & (56) & \\
\hline 2 & 3213 & 180 & (69) & 3353 & 234 & (39) & 3204 & 232 & (30) & $\mathrm{VOH}$ \\
\hline 3 & 3200 & 31 & $(40)$ & 3183 & 4 & $(42)$ & 3144 & 9 & $(47)$ & $\mathrm{vCH}_{3}$ (as) a' \\
\hline 4 & 3163 & 1 & $(82)$ & 3138 & 1 & $(80)$ & 3094 & 2 & (94) & $\mathrm{vCH}_{3}(\mathrm{as}) \mathrm{a}^{\prime \prime}$ \\
\hline 5 & 3080 & 2 & (251) & 3074 & 1 & $(247)$ & 3039 & 2 & $(281)$ & $\mathrm{vCH}_{3}(\mathrm{~s})$ \\
\hline 6 & 1703 & 160 & (9) & 1775 & 176 & (20) & 1696 & 161 & $(12)$ & {$[\mathrm{vCO} / \mathrm{vC}=\mathrm{C}]$ oop } \\
\hline 7 & 1673 & 466 & (132) & 1658 & 599 & (66) & 1638 & 510 & (49) & $[\mathrm{vCO} / \mathrm{vC}=\mathrm{C})] \mathrm{ip} / \mathrm{\delta OH}$ \\
\hline 8 & 1511 & 18 & (5) & 1509 & 37 & (4) & 1496 & 23 & (5) & $\delta \mathrm{CH}_{3}$ (scissoring) a $\mathrm{a}^{\prime} \delta \mathrm{C}_{\mathrm{sp2} 2 \mathrm{H}}$ \\
\hline 9 & 1488 & 9 & (4) & 1476 & 9 & (4) & 1471 & 9 & (5) & $\delta \mathrm{CH}_{3}$ (scissoring) a" \\
\hline 10 & 1471 & 115 & (7) & 1465 & 129 & (10) & 1460 & 115 & (6) & $\delta \mathrm{OH} / \delta \mathrm{CH}_{3}$ (scissoring) a' \\
\hline 11 & 1437 & 37 & (8) & 1430 & 16 & (1) & 1420 & 15 & (4) & {$\left[\delta\left(\mathrm{CH}_{3}\right)\right.$ umbrella / $\left.\mathrm{\delta OH}\right]$ oop } \\
\hline 12 & 1400 & 47 & (44) & 1395 & 23 & (19) & 1390 & 93 & (25) & {$\left[\delta\left(\mathrm{CH}_{3}\right)\right.$ umbrella $\left./ \delta \mathrm{OH}\right]$ ip } \\
\hline 13 & 1349 & 171 & $(44)$ & 1349 & 255 & $(26)$ & 1305 & 161 & (27) & $\mathrm{v}\left(\mathrm{C}-\mathrm{CF}_{3}\right) / \delta \mathrm{OH}$ \\
\hline 14 & 1249 & 176 & (3) & 1279 & 177 & (1) & 1194 & 232 & (1) & $\mathrm{vCF}_{3}(\mathrm{as}) \mathrm{a}^{\prime} / \delta \mathrm{C}_{\mathrm{sp2} 2} \mathrm{H}$ \\
\hline 15 & 1227 & 194 & (8) & 1225 & 170 & (10) & 1220 & 98 & (10) & $\delta \mathrm{C}_{\mathrm{sp} 2} \mathrm{H}$ \\
\hline 16 & 1179 & 268 & (2) & 1214 & 264 & (1) & 1132 & 228 & (2) & $\mathrm{vCF}_{3}(\mathrm{as}) \mathrm{a} "$ \\
\hline 17 & 1134 & 144 & (2) & 1138 & 178 & (1) & 1126 & 243 & (2) & $\delta \mathrm{C}_{\mathrm{sp} 2} \mathrm{H} / \mathrm{v}\left(\mathrm{CO}-\mathrm{C}_{\mathrm{sp} 2} \mathrm{H}\right) / \mathrm{v}\left(\mathrm{CF}_{3}\right)$ \\
\hline 18 & 1066 & 1 & (1) & 1064 & 3 & (1) & 1061 & 1 & (1) & $\rho \mathrm{CH}_{3} \mathrm{a}^{\prime \prime}$ \\
\hline 19 & 1034 & 7 & (1) & 1033 & 7 & (1) & 1033 & 7 & $(0.4)$ & $\rho \mathrm{CH}_{3} \mathrm{a}^{\prime}$ \\
\hline 20 & 962 & 8 & (11) & 968 & 5 & (11) & 958 & 4 & (12) & $\Delta$ \\
\hline 21 & 956 & 62 & $(0.3)$ & 904 & 78 & $(0.3)$ & 942 & 69 & $(0.4)$ & $\mathrm{YOH}$ \\
\hline 22 & 881 & 38 & (1) & 890 & 30 & (1) & 868 & 42 & $(0.4)$ & $\mathrm{v}\left(\mathrm{CH}_{3}-\mathrm{C}\right) / \mathrm{v}\left(\mathrm{C}-\mathrm{CF}_{3}\right)$ \\
\hline 23 & 801 & 32 & (1) & 814 & 25 & $(0.3)$ & 811 & 37 & $(0.4)$ & $\gamma \mathrm{C}_{\mathrm{sp} 2} \mathrm{H}$ \\
\hline 24 & 776 & 3 & $(0.2)$ & 775 & 14 & $(0.2)$ & 771 & 2 & $(0.2)$ & $\Gamma / \gamma \mathrm{C}_{\mathrm{sp2}} \mathrm{H}$ \\
\hline 25 & 741 & 32 & (8) & 749 & 41 & (7) & 728 & 29 & (7) & $\delta \mathrm{CF}_{3}$ (umbrella) \\
\hline 26 & 592 & 0.3 & (2) & 598 & 1 & (2) & 597 & 1 & (2) & $\Gamma$ \\
\hline 27 & 588 & 7 & $(0.2)$ & 591 & 8 & $(0.3)$ & 575 & 5 & (1) & $\delta \mathrm{CF}_{3}$ (scissoring) a' \\
\hline 28 & 531 & 19 & (8) & 528 & 19 & $(6)$ & 532 & 17 & (5) & $\delta(\mathrm{C}-\mathrm{C}-\mathrm{OH})$ \\
\hline 29 & 523 & 3 & $(0.3)$ & 524 & 4 & $(0.3)$ & 513 & 2 & (1) & $\delta \mathrm{CF}_{3}$ (scissoring) a" \\
\hline 30 & 441 & 1 & (2) & 444 & 1 & (1) & 436 & 1 & (1) & $\delta\left(\mathrm{CH}_{3}-\mathrm{C}-\mathrm{C}_{\mathrm{sp} 2}\right) / \delta \mathrm{CF}_{3}$ (scissoring) a \\
\hline 31 & 399 & 4 & $(0.3)$ & 395 & 4 & $(0.3)$ & 403 & 5 & (1) & $\Delta / \delta\left(\mathrm{CH}_{3}-\mathrm{C}(\mathrm{OH})-\mathrm{CH}\right)$ \\
\hline 32 & 323 & 1 & $(2)$ & 325 & 1 & $(2)$ & 320 & 1 & $(2)$ & $\delta\left(\mathrm{CH}_{3}-\mathrm{C}(\mathrm{OH})-\mathrm{CH}\right) / \delta(\mathrm{F}-\mathrm{C}-\mathrm{C}(\mathrm{CO}))$ \\
\hline 33 & 273 & 1 & $(0.1)$ & 273 & 1 & $(0.1)$ & 276 & 2 & (1) & $\Gamma / \rho \mathrm{CF}_{3} \mathrm{a}^{\prime \prime}$ \\
\hline 34 & 268 & 5 & (2) & 252 & 7 & (2) & 264 & 6 & (2) & $\Delta$ \\
\hline 35 & 181 & 0.2 & $(0.4)$ & 178 & 0.4 & $(0.4)$ & 177 & 0 & $(0.4)$ & $\Gamma$ \\
\hline 36 & 143 & 1 & (1) & 138 & 0.3 & $(0.4)$ & 149 & 0.2 & (1) & $\Delta$ \\
\hline 37 & 136 & 1 & $(0.1)$ & 135 & 1 & $(0.1)$ & 127 & 1 & $(0.2)$ & $\tau \mathrm{TCH}_{3}$ \\
\hline 38 & 83 & 0.2 & (2) & 83 & 0.2 & (2) & 86 & 0.2 & (2) & $\Gamma$ \\
\hline 39 & 12 & 2 & (1) & 17 & 2 & (1) & 10 & 2 & (1) & $\mathrm{TCF}_{3}$ \\
\hline
\end{tabular}

$v$ : stretching, $\delta$ : bending, $\rho$ : rocking, $\tau$ : torsion, as: asymmetric, s: symmetric, ip: in phase; oop: out of phase; a' and a" are used to distinguish similar descriptions which correspond to modes of a' or a" symmetries in the approximation of a Cs symmetry with the pseudo-ring plane as the plane of symmetry; $\gamma$ : out-of-plane bending; $\Gamma$ : out-of-plane backbone deformation; $\Delta$ : in-plane backbone deformation; / sign denotes that particular mode is involving vibrations from several groups.

The order of the modes $\{1 \& 2\}$ (in M06-2X), and $\{14 \& 15\}$ (in B3LYP-D3) has been exchanged to match the assignment of the other methods. 
Table 3: Theoretical harmonic frequencies with IR intensities $(\mathrm{km} / \mathrm{mol})$ and Raman scattering activities ( $\AA$ /a.m.u) in parenthesis at the at the MP2/, M06-2X/ and B3LYP$\mathrm{D} 3 / 6-311++\mathrm{G}(3 \mathrm{df}, 3 \mathrm{pd}$ ) levels of theory (unscaled) for $\mathrm{CCC}(\mathrm{OH})$ isomer. The corresponding assignments are also included.

\begin{tabular}{|c|c|c|c|c|c|c|c|c|c|c|}
\hline \multirow{3}{*}{$\begin{array}{c}\text { Mode }^{\mathbf{0}} \\
1\end{array}$} & \multicolumn{10}{|c|}{$\mathrm{CCC}(\mathrm{OH})$} \\
\hline & \multicolumn{3}{|c|}{ MP2 } & \multicolumn{3}{|c|}{ M06-2X } & \multicolumn{3}{|c|}{ B3LYP-D3 } & \multirow{2}{*}{$\begin{array}{l}\text { Assignment-simplified description } \\
\mathrm{vC}_{\mathrm{sp2} 2 \mathrm{H}}\end{array}$} \\
\hline & 3281 & 2 & (49) & 3262 & 3 & (47) & 3240 & 1 & (49) & \\
\hline 2 & 3206 & 6 & (54) & 3186 & 0.2 & (64) & 3148 & 11 & (63) & $\mathrm{vCH}_{3}$ (as) a \\
\hline 3 & 3157 & 2 & (50) & 3132 & 1 & (49) & 3087 & 4 & $(58)$ & $\mathrm{vCH}_{3}$ (as) a" \\
\hline 4 & 3084 & 326 & (125) & 3211 & 351 & (38) & 3079 & 328 & (49) & $\mathrm{VOH}$ \\
\hline 5 & 3073 & 10 & (141) & 3068 & 0.3 & (177) & 3032 & 1 & (192) & $\mathrm{vCH}_{3}(\mathrm{~s})$ \\
\hline 6 & 1713 & 247 & (24) & 1769 & 252 & $(5)$ & 1703 & 269 & (8) & {$[\mathrm{vCO} / \mathrm{vC}=\mathrm{C}]$ oop } \\
\hline 7 & 1671 & 70 & (89) & 1696 & 181 & (87) & 1650 & 140 & (73) & {$[\mathrm{vCO} / \mathrm{vC}=\mathrm{C}]$ ip $/ \delta \mathrm{OH}$} \\
\hline 8 & 1492 & 9 & (4) & 1478 & 9 & (5) & 1474 & 9 & (5) & $\delta \mathrm{CH}_{3}$ (scissoring) a" \\
\hline 9 & 1488 & 33 & (6) & 1496 & 46 & (3) & 1469 & 13 & (3) & $\mathrm{v}(\mathrm{C}-\mathrm{OH}) / \delta \mathrm{C}_{\mathrm{sp} 2} \mathrm{H} / \delta \mathrm{CH}_{3}$ (scissoring) $\mathrm{a}^{\prime}$ \\
\hline 10 & 1478 & 22 & (8) & 1469 & 19 & $(7)$ & 1464 & 41 & (6) & $\delta \mathrm{CH}_{3}$ (scissoring) a \\
\hline 11 & 1418 & 159 & (41) & 1406 & 170 & $(10)$ & 1402 & 97 & $(11)$ & {$\left[\delta \mathrm{CH}_{3}\right.$ (umbrella) / $\left.\mathrm{\delta OH}\right]$ oop } \\
\hline 12 & 1393 & 60 & (30) & 1381 & 81 & (25) & 1385 & 69 & (26) & {$\left[\delta \mathrm{CH}_{3}\right.$ (umbrella) / $\left.\delta \mathrm{OH}\right]$ ip } \\
\hline 13 & 1332 & 452 & (2) & 1328 & 458 & (3) & 1294 & 495 & (5) & $\mathrm{v}\left(\mathrm{C}-\mathrm{CF}_{3}\right) / \delta \mathrm{OH} / \delta \mathrm{C}_{\mathrm{sp} 2} \mathrm{H}$ \\
\hline 14 & 1241 & 152 & (1) & 1239 & 23 & (2) & 1231 & 65 & (2) & $\delta \mathrm{C}_{\mathrm{sp} 2} \mathrm{H} / \delta \mathrm{CH}_{3}$ (scissoring) a' \\
\hline 15 & 1227 & 191 & (3) & 1264 & 377 & (2) & 1180 & 288 & (3) & $\mathrm{vCF}_{3}$ (as) a' \\
\hline 16 & 1203 & 276 & (3) & 1239 & 273 & (3) & 1152 & 278 & (3) & $\mathrm{vCF}_{3}$ (as) a" \\
\hline 17 & 1134 & 58 & (4) & 1148 & 58 & $(5)$ & 1136 & 84 & $(4)$ & $\delta \mathrm{C}_{\mathrm{sp} 2} \mathrm{H}$ \\
\hline 18 & 1050 & 1 & (0) & 1052 & 6 & (0) & 1049 & 3 & (0) & $\rho \mathrm{CH}_{3} \mathrm{a}^{\prime \prime}$ \\
\hline 19 & 1006 & 12 & (11) & 1005 & 14 & (9) & 1002 & 19 & (8) & $\Delta / \rho \mathrm{CH}_{3} \mathrm{a}^{\prime}$ \\
\hline 20 & 973 & 53 & $(0.3)$ & 921 & 62 & $(0.3)$ & 955 & 56 & (1) & $\mathrm{YOH}$ \\
\hline 21 & 940 & 8 & (5) & 938 & 12 & (4) & 936 & 10 & (5) & $\Delta / \rho \mathrm{CH}_{3} \mathrm{a}^{\prime}$ \\
\hline 22 & 866 & 11 & (2) & 873 & 7 & $(2)$ & 850 & 14 & (2) & $\mathrm{v}\left(\mathrm{CH}_{3}-\mathrm{C}\right) / \mathrm{v}\left(\mathrm{C}-\mathrm{CF}_{3}\right)$ \\
\hline 23 & 819 & 38 & (1) & 834 & 41 & (1) & 830 & 41 & (1) & $\gamma \mathrm{C}_{\mathrm{sp} 2} \mathrm{H}$ \\
\hline 24 & 738 & 2 & $(0.3)$ & 745 & 6 & $(0.3)$ & 735 & 2 & $(0.3)$ & $\Gamma / \gamma \mathrm{C}_{\mathrm{sp2} 2} \mathrm{H}$ \\
\hline 25 & 733 & 11 & (10) & 736 & 14 & $(7)$ & 721 & 10 & $(8)$ & $\delta \mathrm{CF}_{3}$ (umbrella) \\
\hline 26 & 604 & 0 & (0) & 608 & 0 & (0) & 609 & 0 & (0.1) & $\Gamma$ \\
\hline 27 & 595 & 2 & (2) & 599 & 3 & (2) & 577 & 21 & $(1)$ & $\delta \mathrm{CF}_{3}$ (scissoring) a' \\
\hline 28 & 581 & 46 & (3) & 585 & 50 & (3) & 589 & 24 & (3) & $\delta\left(\mathrm{CH}_{3}-\mathrm{C}-\mathrm{O}\right)$ \\
\hline 29 & 522 & 1 & (1) & 525 & 1 & (1) & 513 & 1 & (1) & $\delta \mathrm{CF}_{3}$ (scissoring) a" \\
\hline 30 & 436 & 1 & $(0.4)$ & 438 & 1 & (0.4) & 431 & 1 & $(0.3)$ & $\delta\left(\mathrm{CH}_{3}-\mathrm{C}-\mathrm{C}\right) / \delta \mathrm{CF}_{3}$ (scissoring) a \\
\hline 31 & 376 & 3 & (1) & 366 & 4 & (1) & 378 & 4 & (1) & $\Delta$ \\
\hline 32 & 308 & 1 & (3) & 308 & 1 & (4) & 305 & 1 & (4) & $\Delta$ \\
\hline 33 & 303 & 0 & $(0.2)$ & 302 & 0 & $(0.3)$ & 301 & 0 & $(0.2)$ & $\Gamma$ \\
\hline 34 & 284 & 2 & $(0.3)$ & 268 & 3 & $(0.3)$ & 284 & 2 & (1) & $\Delta$ \\
\hline 35 & 159 & 3 & (1) & 154 & 4 & $(0.4)$ & 161 & 4 & $(0.4)$ & $\Delta$ \\
\hline 36 & 135 & 1 & (1) & 132 & 1 & (1) & 135 & 1 & $(0.3)$ & $\Gamma$ \\
\hline 37 & 120 & 1 & (1) & 121 & 1 & (1) & 120 & 2 & (1) & $\Gamma$ \\
\hline 38 & 88 & 1 & (0) & 96 & 1 & $(0.1)$ & 78 & 0.4 & (0) & $\tau \mathrm{TCH}_{3}$ \\
\hline 39 & 40 & 1 & (1) & 39 & 1 & $(1)$ & 37 & 1 & (1) & $\mathrm{TCF}_{3}$ \\
\hline
\end{tabular}

$v$ : stretching, $\delta$ : bending, $\rho$ : rocking, $\tau$ : torsion, as: asymmetric, s: symmetric, ip: in phase; oop: out of phase; a' and a" are used to distinguish similar descriptions which correspond to modes of a' or a" symmetries in the approximation of a Cs symmetry with the pseudo-ring plane as the plane of symmetry; $\gamma$ : out-of-plane bending; $\Gamma$ : out-of-plane backbone deformation; $\Delta$ : in-plane backbone deformation; / - sign denotes that particular mode is involving vibrations from several groups

The order of the modes $\{2,3 \& 4\} ;\{8 \& 9\} ;\{14 \& 16\} ;$ and $\{20 \& 21\}$ has been exchanged in M06-2X to match the assignment of the other methods. 


\section{Experimental results}

1) Raman spectroscopy

Raman spectroscopy brings very important data which complements the results from infrared spectroscopy experiments. As shown by the theoretical calculations (Tables 2 and 3), several modes with almost no IR intensity can be observed in Raman, giving access to additional modes. Others have both IR and Raman responses and can help in confirming the assignment to one isomer or the other. On the other hand, Raman spectroscopy enables us to observe bands in the low frequency range.

We thus performed Raman spectroscopy of TFacac in $\mathrm{Ar}$ and $\mathrm{N}_{2}$ matrices, to complement the results of ref. 23. Several bands, absent or weak in Ar, are clearly observed in $\mathrm{N}_{2}$. Experiments in $\mathrm{CO}$ and $\mathrm{Xe}$ were also conducted to explore slightly different environments: the CO lattice is very similar to the $\mathrm{N}_{2}$ one. ${ }^{34}$ Xe serves as another rare gas and was used in order to compare the results to those in $\mathrm{Ar}$ matrix.

The most significant parts of the Raman spectra in the four matrices are shown in Figure 3. Obviously, $\mathrm{CO}$ and $\mathrm{N}_{2}$ spectra are very similar and contain more bands than Ar and Xe spectra. It is especially evident in the low energy range (Figure 3, right panel), where bands are quite narrow and thus easier to assign. Specific to $\mathrm{CO}$ and $\mathrm{N}_{2}$ spectra, bands at 310 and $575 \mathrm{~cm}^{-1}$ are in very good agreement with $\mathrm{CCC}(\mathrm{OH})$ modes calculated at 308.1 and $584.7 \mathrm{~cm}^{-1}$ (M06-2X unscaled values). Many other bands, more intense in $\mathrm{CO}$ and $\mathrm{N}_{2}$, can be attributed to the $\mathrm{CCC}(\mathrm{OH})$ isomer. Raman bands are collected in Table 4 with their assignments. Bands with intense Raman activities are theoretically predicted close to $1400 \mathrm{~cm}^{-1}$ for both isomers (cf Tables 2 and 3). Experimentally, bands are very broad in the $1200-1400 \mathrm{~cm}^{-1}$ spectral window (Figure 3, right panel) and there is no clear evidence of additional bands in $\mathrm{CO}$ and $\mathrm{N}_{2}$, compared to Ar and Xe. A band around $1280 \mathrm{~cm}^{-1}$ is especially broad and intense. It corresponds to a mode of the $\mathrm{CCC}(\mathrm{CO})$ isomer involving $\mathrm{OH}$ in-plane bending correlated with pseudo-cycle motions favoring the $\mathrm{H}$ transfer. This band is structured, with at least three maxima ( 1303 $\mathrm{cm}^{-1}$ - weak -, $\sim 1285 \mathrm{~cm}^{-1}$ and $\sim 1275 \mathrm{~cm}^{-1}$ ), but seems not to be altered by the $\mathrm{CCC}(\mathrm{OH})$ similar mode, predicted to have low Raman activity. The assignment of the intense $\mathrm{CCC}(\mathrm{OH})$ band calculated around $1380 \mathrm{~cm}^{-1}$ is tentative, this band can be hidden under the broad $\mathrm{CCC}(\mathrm{CO})$ features. The other intense $\mathrm{CCC}(\mathrm{OH})$ band above $1600 \mathrm{~cm}^{-1}$ is more clearly attributed to the blue side band $\left(\sim 1627 \mathrm{~cm}^{-1}\right)$ of the most intense Raman band at $1608 \mathrm{~cm}^{-1}$ of $\mathrm{CCC}(\mathrm{CO})$ isomer. The high frequency range is shown in Figure 3 , left panel. All the $\mathrm{C}-\mathrm{H}$ stretching modes of the $\mathrm{CCC}(\mathrm{CO})$ isomer are observed. $\mathrm{C}-\mathrm{H}$ stretching modes of the other isomer could be hidden under these bands, because they are experimentally broad (bandwidths $>10 \mathrm{~cm}^{-1}$ ) and theoretically predicted at very similar frequencies for both isomers.

Importantly, the analysis of Raman spectra highlights the presence of $\mathrm{CCC}(\mathrm{OH})$ in the four matrices. However, $\mathrm{CCC}(\mathrm{OH})$ is obviously a minor isomer in $\mathrm{Ar}$ and $\mathrm{Xe}$. 

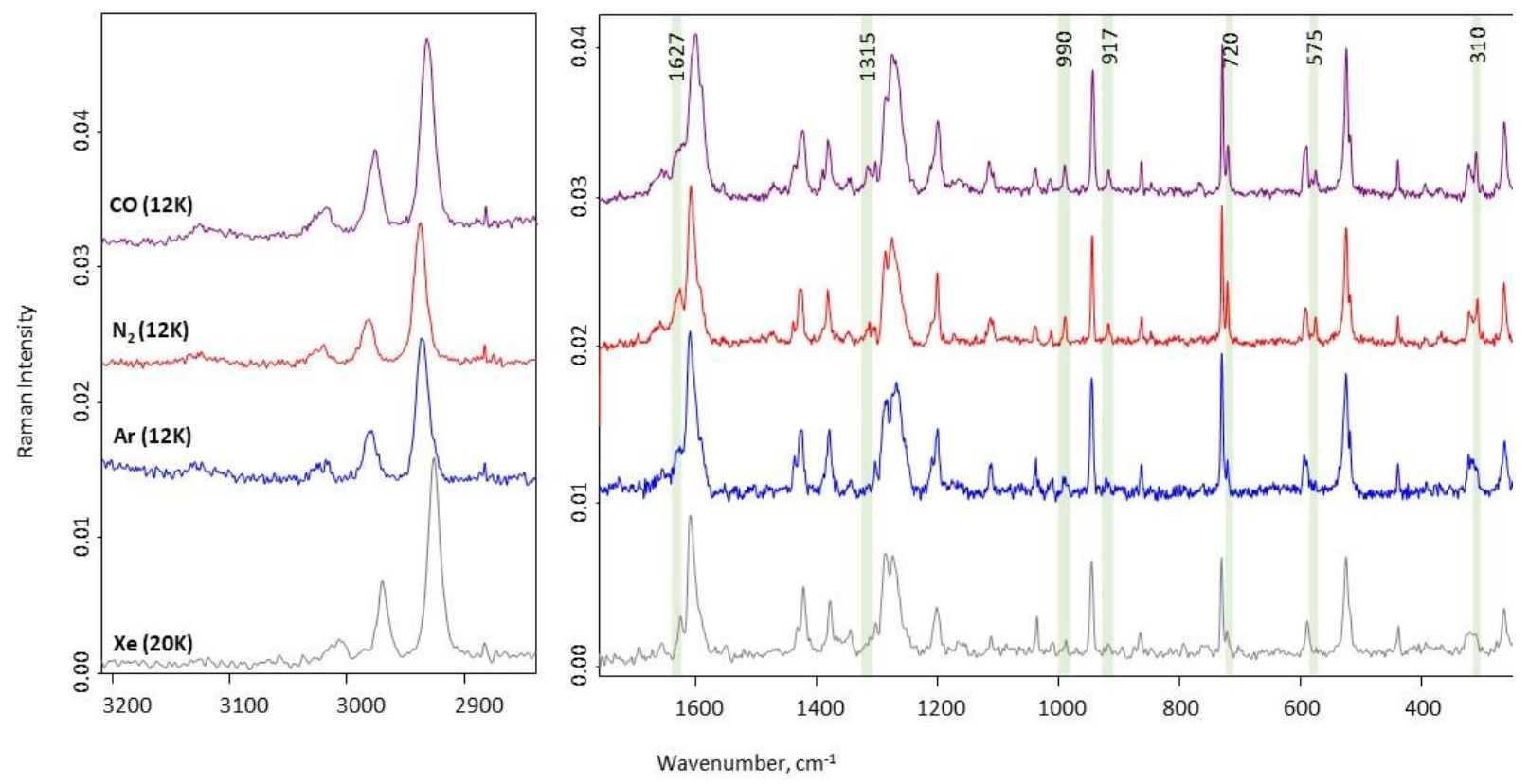

Figure 3: Raman spectra in $\mathrm{CO}$ (violet), $\mathrm{N}_{2}$ (red), $\operatorname{Ar}$ (blue) ( $\mathrm{T}=12 \mathrm{~K}$ ) and $\mathrm{Xe}$ (grey) ( $\mathrm{T}=20 \mathrm{~K}$ ) matrices in two spectral ranges: $\mathrm{C}-\mathrm{H}$ stretching range (left panel) and $1750-250 \mathrm{~cm}^{-1}$ (right panel). Green vertical strips highlight $\mathrm{CCC}(\mathrm{OH})$ bands in the right panel. Spectra in $\mathrm{Ar}, \mathrm{CO}$ and $\mathrm{N}_{2}$ are vertically shifted for better visibility.

Table 4: Experimental band frequencies (in $\mathrm{cm}^{-1}$ ) observed in Raman spectra of TFacac isolated in CO, $\mathrm{N}_{2}$, Ar and Xe matrices. Theoretical values (M06-2X/6-311++G(3df,3pd) level of theory, unscaled) for both $\mathrm{CCC}(\mathrm{CO})$ and $\mathrm{CCC}(\mathrm{OH})$ isomers are added for comparison and assignments. Bands assigned to $\mathrm{CCC}(\mathrm{OH})$ in bold. Relative intensities (qualitative) are reported in $\mathrm{N}_{2}$.

\begin{tabular}{|c|c|c|c|c|c|}
\hline \multicolumn{4}{|c|}{ Experimental } & Theoretical & Assignment $^{\mathrm{a}}$ \\
\hline CO & $\mathrm{N}_{2}^{\mathrm{b}}$ & $\mathrm{Ar}$ & $\mathrm{Xe}$ & M06-2X & \\
\hline 3126 & $3130 w$ & 3130 & & 3257 & $\mathrm{vC}_{\mathrm{sp} 2} \mathrm{H}$ \\
\hline 3017 & $3019 \mathrm{~m}$ & 3020 & 3006 & 3183 & $\mathrm{vCH}_{3}$ (as) a' \\
\hline 2977 & $2981 \mathrm{~s}$ & 2979 & 2970 & 3138 & $\mathrm{vCH}_{3}$ (as) a" \\
\hline 2932 & 2937 vs & 2935 & 2926 & 3074 & $\mathrm{vCH}_{3}(\mathrm{~s})$ \\
\hline 1657 & $1657 \mathrm{wm}$ & 1654 & 1657 & 1775 & {$[\mathrm{vCO} / \mathrm{vC}=\mathrm{C}]$ oop } \\
\hline 1627 & $1628 \mathrm{~m}$ & 1628 & 1625 & 1696 & {$[\mathrm{vCO} / \mathrm{vC}=\mathrm{C}]$ ip / $\delta \mathrm{OH}$} \\
\hline 1600 & $1608 \mathrm{~s}$ & 1608 & 1608 & 1658 & {$[\mathrm{vCO} / \mathrm{vC}=\mathrm{C}]$ ip / $\mathrm{\delta OH}$} \\
\hline 1471 & $1471 \mathrm{w}$ & & & 1509 & $\delta \mathrm{CH}_{3}$ (scissoring) a $/ \delta \mathrm{C}_{\mathrm{sp} 2} \mathrm{H}$ \\
\hline 1438 & $1438 \mathrm{sh}$ & 1436 & 1431 & 1475 & $\mathrm{\delta CH}_{3}$ (scissoring) a" \\
\hline 1423 & $1426 \mathrm{~m}$ & 1425 & 1421 & 1465 & $\delta \mathrm{OH} / \delta \mathrm{CH}_{3}$ (scissoring) a' \\
\hline 1391 & $1390 \mathrm{vw}$, sh & 1390 & & $1381^{d}$ & \\
\hline 1381 & $1381 \mathrm{~m}$ & 1379 & 1377 & 1395 & {$\left[\mathrm{\delta CH}_{3}\right.$ (umbrella) / $\left.\mathrm{\delta OH}\right] \mathrm{ip}$} \\
\hline 1346 & $1348 \mathrm{w}$ & 1345 & & $1395^{d}$ & \\
\hline 1315 & $1313 \mathrm{vw}$ & & & 1381 & {$\left[\delta \mathrm{CH}_{3}\right.$ (umbrella) / $\left.\delta \mathrm{OH}\right]$ ip } \\
\hline 1302 & $1303 w$ & 1303 & 1302 & & $\mathrm{v}\left(\mathrm{C}-\mathrm{CF}_{3}\right) / \delta \mathrm{OH}$ \\
\hline $1286^{c}$ & $1286^{\mathrm{C}}$ vs & $1285^{c}$ & $1286^{c}$ & 1349 & \\
\hline $1275^{\mathrm{c}}$ & $1275^{\circ}$ vs & $1272^{c}$ & $1274^{c}$ & & \\
\hline 1210 & $1210 \mathrm{~m}, \mathrm{sh}$ & 1210 & 1210 & 1279 & $\mathrm{vCF}_{3}(\mathrm{as}) \mathrm{a}^{\prime} / \delta \mathrm{C}_{\mathrm{sp2} 2} \mathrm{H}$ \\
\hline 1200 & $1200 \mathrm{~m}$ & 1200 & 1200 & 1225 & $\delta \mathrm{C}_{\mathrm{sp} 2} \mathrm{H}$ \\
\hline 1114 & $1113 \mathrm{w}$ & 1112 & 1113 & 1148 & $\delta \mathrm{C}_{\mathrm{sp2} 2 \mathrm{H}}$ \\
\hline 1108 & $1108 \mathrm{w}$ & & & 1138 & $\delta \mathrm{C}_{\mathrm{sp} 2} \mathrm{H} / \mathrm{v}\left(\mathrm{CO}-\mathrm{C}_{\mathrm{sp} 2} \mathrm{H}\right) / \mathrm{v}\left(\mathrm{CF}_{3}\right)$ \\
\hline 1039 & $1038 \mathrm{w}$ & 1037 & 1036 & 1064 & $\rho \mathrm{CH}_{3} \mathrm{a}^{\prime \prime}$ \\
\hline 1014 & $1012 \mathrm{vw}$ & 1011 & $1011^{d}$ & 1033 & $\rho \mathrm{CH}_{3} \mathrm{a}^{\prime}$ \\
\hline
\end{tabular}




\begin{tabular}{|c|c|c|c|c|c|}
\hline 990 & $989 \mathrm{w}$ & $989^{d}$ & & 1005 & $\Delta / \rho \mathrm{CH}_{3} \mathrm{a}^{\prime}$ \\
\hline 944 & $944 \mathrm{~s}$ & 945 & 945 & 967 & $\Delta$ \\
\hline 917 & $917 \mathrm{w}$ & $918^{d}$ & $919^{d}$ & 938 & $\Delta / \rho \mathrm{CH}_{3} \mathrm{a}^{\prime}$ \\
\hline 863 & $863 \mathrm{w}$ & 863 & 864 & 890 & $\mathrm{v}\left(\mathrm{CH}_{3}-\mathrm{C}\right) / \mathrm{v}\left(\mathrm{C}-\mathrm{CF}_{3}\right)$ \\
\hline $847^{d}$ & $847^{d} v w$ & & & 873 & $\mathrm{v}\left(\mathrm{CH}_{3}-\mathrm{C}\right) / \mathrm{v}\left(\mathrm{C}-\mathrm{CF}_{3}\right)$ \\
\hline $767^{d}$ & $765^{d}$ vvw & $762^{d}$ & $762^{d}$ & 775 & $\Gamma / \gamma \mathrm{C}_{\mathrm{sp} 2} \mathrm{H}$ \\
\hline 729 & $730 \mathrm{~s}$ & 730 & 731 & 749 & $\delta \mathrm{CF}_{3}$ (umbrella) \\
\hline 720 & $721 \mathrm{~m}$ & 721 & 722 & 736 & $\delta C_{3}$ (umbrella) \\
\hline 590 & $593 \mathrm{~m}$ & 591 & 589 & 598 & $\Gamma$ \\
\hline 575 & $575 \mathrm{w}$ & $576^{d}$ & & 585 & $\delta\left(\mathrm{CH}_{3}-\mathrm{C}-\mathrm{O}\right)$ \\
\hline 25 & $526 \mathrm{~s}$ & 525 & 526 & 528 & $\delta(\mathrm{C}-\mathrm{C}-\mathrm{OH})$ \\
\hline 518 & $517 \mathrm{sh}$ & 519 & 518 & 524 & $\delta \mathrm{CF}_{3}$ (scissoring) a" \\
\hline 440 & $441 \mathrm{w}$ & 439 & 440 & 444 & $\delta\left(\mathrm{CF}_{3}-\mathrm{C}_{-} \mathrm{C}_{\mathrm{sp} 2}\right) / \delta \mathrm{CF}_{3}$ (scissoring) a' \\
\hline $395^{d}$ & $394^{d}$ vw & $393^{d}$ & & 395 & $\Delta / \delta\left(\mathrm{CH}_{3}-\mathrm{C}(\mathrm{OH})-\mathrm{CH}\right)$ \\
\hline $372^{d}$ & $371^{d} v w$ & & & 366 & $\Delta$ \\
\hline 323 & $324 \mathrm{w}$ & 322 & 320 & 325 & $\delta\left(\mathrm{CH}_{3}-\mathrm{C}(\mathrm{OH})-\mathrm{CH}\right) / \delta(\mathrm{F}-\mathrm{C}-\mathrm{C}(\mathrm{CO}))$ \\
\hline 310 & $314 \mathrm{w}$ & $310^{d}$ & $311^{d}$ & 308 & $\Delta$ \\
\hline $300^{d}$ & $300^{d} \mathrm{vVw}$ & & & 302 & $\Gamma$ \\
\hline 264 & $264 \mathrm{wm}$ & 263 & 264 & 252 & $\Delta$ \\
\hline 190 & $192 \mathrm{w}$ & 186 & 185 & 178 & $\Gamma$ \\
\hline
\end{tabular}

${ }^{a}$ same notations and descriptions as in Tables 2 and 3

${ }^{\mathrm{b}} \mathrm{s}$-strong, m-medium, w- weak, vw-very weak, sh-shoulder

${ }^{c}$ broad intense doublet (see text)

${ }^{d}$ tentative

2) Infrared Spectroscopy

a) General features

Infrared spectra were obtained in different matrices: $\mathrm{Ar}$ and $\mathrm{Ne}$ (rare gas), $\mathrm{N}_{2}$ and $\mathrm{CO}$ (diatomic, more intrusive hosts) and $p \mathrm{H}_{2}$ (very soft host). Additional data were obtained in normal hydrogen $\left(n \mathrm{H}_{2}\right)$ in order to test the influence of ortho-hydrogen $\left(\mathrm{oH}_{2}\right)$ on TFacac. No significant changes between $p \mathrm{H}_{2}$ and $n \mathrm{H}_{2}$ spectra were detected and only spectra in $p \mathrm{H}_{2}$ are discussed hereafter. Figure 4 shows the main parts of the spectra in the five hosts. As with Raman results, additional bands are clearly observed in $\mathrm{N}_{2}$ and $\mathrm{CO}$. Some of them have the same frequencies in Raman and IR and correspond to modes of $\mathrm{CCC}(\mathrm{OH})$ where both IR and Raman activities are intense. Table 5 reports the observed band frequencies and their assignment to one or the other CCC isomer. In Figure 4, CCC(OH) bands are highlighted by light green vertical strips. $\mathrm{CCC}(\mathrm{OH})$ is much more populated in $\mathrm{N}_{2}$ and $\mathrm{CO}$ than in $\mathrm{Ar}$ and very weakly detected in Ne. Surprisingly, it is more populated in $\mathrm{pH}_{2}$ than in $\mathrm{Ne}$ at the same temperature. The host dependence of $\mathrm{CCC}(\mathrm{OH})$ amount is especially clear when looking at the bands around $800 \mathrm{~cm}^{-1}$ : it is the spectral range of $\mathrm{C}-\mathrm{H}$ out-of-plane bending mode $\left(\gamma \mathrm{C}_{\mathrm{sp} 2} \mathrm{H}\right)$ in both isomers. This mode is predicted with a higher IR intensity in $\mathrm{CCC}(\mathrm{OH})$ than in $\mathrm{CCC}(\mathrm{CO})$ and the band is quite intense in $\mathrm{N}_{2}$ and $\mathrm{CO}$. Moreover, both $\gamma \mathrm{C}_{\mathrm{sp} 2} \mathrm{H}$ bands exhibit a structure, linked to the existence of different trapping sites.

As in the Raman spectra, the bands are easily assigned below $1100 \mathrm{~cm}^{-1}$ (Figure 4, right panel) due to generally narrow bandwidths. The exception is the $\mathrm{O}-\mathrm{H}$ out-of-plane bending mode $(\gamma \mathrm{OH})$ in both isomers, a mode especially sensitive to the internal $\mathrm{H}$-bond, not observed in Raman. From the previously described dependence of $\mathrm{CCC}(\mathrm{OH})$ on the host, the band close to $900 \mathrm{~cm}^{-1}$ only observed clearly in $\mathrm{N}_{2}\left(898 \mathrm{~cm}^{-1}\right)$ and $\mathrm{CO}\left(894 \mathrm{~cm}^{-1}\right)$, is assigned to $\gamma \mathrm{OH}$ in this isomer. $\gamma \mathrm{OH}$ in $\mathrm{CCC}(\mathrm{CO})$ is theoretically predicted at a lower frequency, with a higher intensity, but seems to correspond to the 
broad and structured feature observed in this spectral range in $\mathrm{Ar}$ (noted at $910 \mathrm{~cm}^{-1}$ in ref. 23). A narrower band at $884 \mathrm{~cm}^{-1}$ in $\mathrm{Ne}$ (at $882.5 \mathrm{~cm}^{-1}$ in $\mathrm{pH}_{2}$ ) could correspond to $\gamma \mathrm{OH}$ in $\mathrm{CCC}(\mathrm{CO})$. However, a broader band at $915 \mathrm{~cm}^{-1}\left(921\right.$ in $\mathrm{pH}_{2}$ ) also seems to be a good candidate for the assignment to a vibrational mode involved in the $\mathrm{H}$ bond due to its bandwidth. $\mathrm{A}$ band around 915 $\mathrm{cm}^{-1}$ is detected in Raman spectra and assigned to the $\mathrm{CCC}(\mathrm{OH})$ isomer. It cannot be the same mode in IR because its host dependence allows an assignment to $\mathrm{CCC}(\mathrm{CO})$. We conclude that both features could belong to the out-of-plane $\mathrm{OH}$ bending mode in $\mathrm{CCC}(\mathrm{CO})$. A complex structure is also observed for the in-plane $\mathrm{OH}$ bending mode in $\mathrm{CCC}(\mathrm{CO})$ (see below and Raman results).

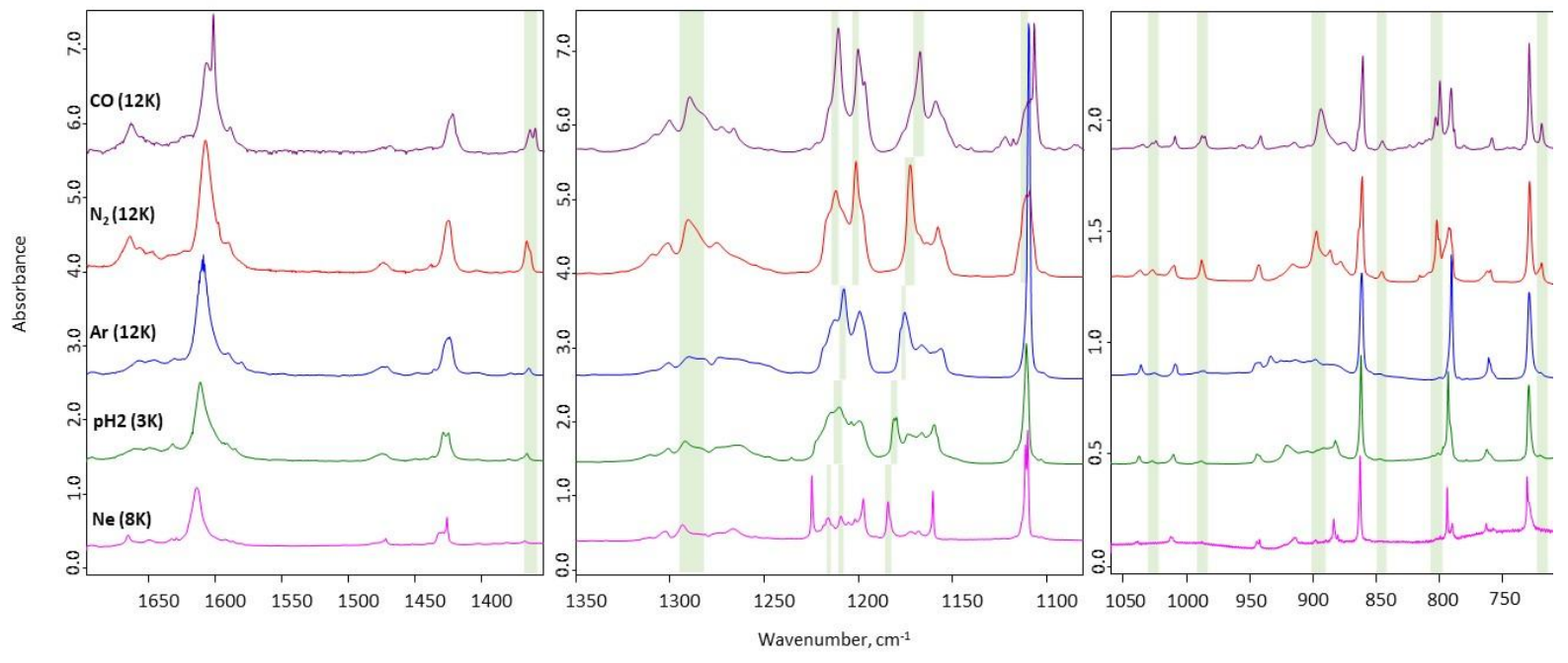

Figure 4: IR spectra in $\mathrm{CO}$ (violet), $\mathrm{N}_{2}$ (red), $\mathrm{Ar}$ (blue), $\mathrm{pH}_{2}$ (green) and $\mathrm{Ne}$ (pink) matrices ( $\mathrm{T}=$ (range 3$12 \mathrm{~K})$ ) in three spectral ranges: $700-1060 \mathrm{~cm}^{-1}$ (right panel), $1080-1350 \mathrm{~cm}^{-1}$ (middle panel), and 1300$1700 \mathrm{~cm}^{-1}$ (left panel). Green vertical strips highlight main $\mathrm{CCC}(\mathrm{OH})$ bands. Spectra in $p \mathrm{H}_{2}, \mathrm{Ar}, \mathrm{CO}$ and $\mathrm{N}_{2}$ are vertically shifted for better visibility.

Figure 4, middle panel, shows the complex spectral range involving many intense bands of both isomers. As the spectra are strongly host dependent, the assignments are not at all clear. Moreover, the theoretical predictions are also strongly method dependent and their helpfulness is reduced. An intense IR mode of $\mathrm{CCC}(\mathrm{CO})$ is theoretically predicted at a slightly lower frequency than a mode of $\mathrm{CCC}(\mathrm{OH})$ with a medium Raman activity in the $1140-1120 \mathrm{~cm}^{-1}$ spectral range. One can guess a slight red shift of the band around $1110 \mathrm{~cm}^{-1}$ from Raman to IR spectra in $\mathrm{Ar}, \mathrm{N}_{2}$ and $\mathrm{CO}$. We conclude that there is an overlap of both bands: at $1111-1114 \mathrm{~cm}^{-1}$ in $\mathrm{CCC}(\mathrm{OH})$ and at $1107-1111 \mathrm{~cm}^{-1}$ in $\mathrm{CCC}(\mathrm{CO})$ (see Tables 4 and 5). Two groups of bands especially puzzling around 1170 and $1200 \mathrm{~cm}^{-1}$ were assigned by comparison with the IR spectrum of hexafluoroacetylacetone (HFacac) ${ }^{35,36}$. In HFacac all the modes of this spectral range correspond to different $\mathrm{C}-\mathrm{F}$ stretching modes of the $\mathrm{CF}_{3}$ groups and can easily be assigned to $\mathrm{CF}_{3}$ modes either on the $\mathrm{OH}$ side or on the $\mathrm{CO}$ side. ${ }^{24}$ Obviously, the amount of strong bands in this range of TFacac spectra reflects the co-existence of both isomers. The additional experimental results described below (see $\S b$ ) confirm this first conclusion. The detailed assignment proposed in Table 5 is based on the analysis of all the collected data (see $\S c$ ) below). As in the Raman spectrum, the intense mode around $1300 \mathrm{~cm}^{-1}$ involving in-plane $\mathrm{OH}$ bending of $\mathrm{CCC}(\mathrm{CO})$ is large and structured. The similar mode of $\mathrm{CCC}(\mathrm{OH})$, in the same frequency range, has a weak Raman intensity but a very strong IR intensity. It corresponds thus to the broad peak observed above the large structure in $\mathrm{N}_{2}$ and $\mathrm{CO}$ at $\sim 1290 \mathrm{~cm}^{-1}$. 
Assignments of bands shown in the left panel of Figure 4 are more straightforward. The comparison with Raman spectra and between different hosts allow a better attribution and the two $(C=C, C=0)$ stretching modes of each isomer: $\sim 1610$ and $\sim 1650 \mathrm{~cm}^{-1}$ for $\mathrm{CCC}(\mathrm{CO})$, and $\sim 1625$ and $\sim 1660 \mathrm{~cm}^{-1}$ for $\mathrm{CCC}(\mathrm{OH})$. One can observe the presence of a $\mathrm{CCC}(\mathrm{OH})$ band at $\sim 1365 \mathrm{~cm}^{-1}$, quite isolated from the $\mathrm{CCC}(\mathrm{CO})$ manifold, which can serve as a detector of the second isomer.

C-H stretching modes appear as very weak broad bands and have only been measured in concentrated samples (values reported in Table 5). The O-H stretching mode, with high IR intensity, forms a too broad band due to the internal $\mathrm{H}$-bond, making it difficult to separate from the background.

Table 5: Experimental band frequencies (in $\mathrm{cm}^{-1}$ ) observed in IR spectra of TFacac isolated in $\mathrm{CO}, \mathrm{N}_{2}$, $\mathrm{Ar}, \mathrm{Ne}$ and $\mathrm{pH}_{2}$ matrices. Bands assigned to $\mathrm{CCC}(\mathrm{OH})$ in bold. Corresponding predicted values (unscaled) of the modes at the M06-2X/6-311++G(3df,3pd) level of theory are reported for comparison, with their simplified description. Relative intensities are indicated qualitatively.

\begin{tabular}{|c|c|c|c|c|c|c|}
\hline \multicolumn{5}{|c|}{ Experimental $^{\mathrm{a}}$} & Calculated & \multirow{2}{*}{ Assignment $^{c}$} \\
\hline CO & N2 & $\overline{A r}$ & $\mathrm{Ne}$ & $p \mathrm{H} 2$ & M06-2X & \\
\hline 3022 & $3027^{d}$ & & $3032^{d}$ & $3026^{d}$ & $3186 \mathrm{vw}$ & $\mathrm{vCH}_{3}$ (as) a' \\
\hline 3014 & 3020 & 3019 & 3021 & 3016 & $3183 \mathrm{vw}$ & $\mathrm{vCH}_{3}$ (as) a' \\
\hline 2980 & & 2980 & 2980 & 2977 & $3138 \mathrm{vw}$ & $\mathrm{vCH}_{3}$ (as) a" \\
\hline 2968 & & & & $2971^{d}$ & $3132 \mathrm{vw}$ & $\mathrm{vCH}_{3}$ (as) a" \\
\hline 2932 & & $2933^{d}$ & $2933^{d}$ & 2932 & $3074 \mathrm{vw}$ & $\mathrm{vCH}_{3}(\mathrm{~s})$ \\
\hline $1665 \mathrm{~m}$ & $1664 \mathrm{~m}$ & $1658 w$ & $1666 \mathrm{w}$ & $1661 \mathrm{w}$ & 1769.0 vs & [vCO / vC=C] oop \\
\hline $1653 \mathrm{w}$ & $1654 \mathrm{w}$ & $1646 \mathrm{w}$ & $1650 \mathrm{w}$ & $1649 w$ & $1774.5 \mathrm{~s}$ & {$[\mathrm{vCO} / \mathrm{vC}=\mathrm{C}]$ oop } \\
\hline $1623 \mathrm{w}$ & $1623 \mathrm{w}$ & $1631 \mathrm{w}$ & $1633 \mathrm{vw}$ & & $1695.8 \mathrm{~s}$ & $[v C O / v C=C)]$ ip / $\delta O H$ \\
\hline $1607 \mathrm{~s}$ & $1607 \mathrm{~s}$ & $1609 \mathrm{~s}$ & $1614 \mathrm{~s}$ & $1611.5 \mathrm{~s}$ & 1657.7 vvs & $[\mathrm{vCO} / \mathrm{vC}=\mathrm{C})]$ ip / $\delta \mathrm{OH}$ \\
\hline $1470 \mathrm{vw}$ & $1473 w$ & $1473 w$ & $1471.5 \mathrm{w}$ & $1472 w$ & $1508.9 \mathrm{w}$ & $\delta \mathrm{CH}_{3}$ (scissoring) $\mathrm{a}^{\prime} / \delta \mathrm{C}_{\mathrm{sp} 2} \mathrm{H}$ \\
\hline $1422.5 \mathrm{w}$ & $1425 \mathrm{~m}$ & $1424 \mathrm{~m}$ & $\begin{array}{c}1425.5 \mathrm{~m} \\
1429 \mathrm{~m}, \mathrm{sh}\end{array}$ & $\begin{array}{c}1424 \mathrm{w} \\
1428.5 \mathrm{w}\end{array}$ & $1465.1 \mathrm{~s}$ & $\delta \mathrm{OH} / \delta \mathrm{CH}_{3}$ (scissoring) a' \\
\hline $\begin{array}{l}1360 \mathrm{w} \\
1363.5\end{array}$ & $\begin{array}{c}1365.5 \mathrm{w} \\
1363\end{array}$ & 1364 vw & 1367 vvw & $1365 \mathrm{vvw}$ & $1406.1 \mathrm{~s}$ & {$\left[\delta \mathrm{CH}_{3}\right.$ (umbrella) / $\left.\delta \mathrm{OH}\right]$ oop } \\
\hline $\begin{array}{c}1301 \mathrm{w} \\
1284 \\
\text { br, struct }\end{array}$ & $\begin{array}{c}1301 \\
1285 \\
1275 \\
\text { br, struct }\end{array}$ & $\begin{array}{c}1301 \\
1283 \\
1273 \\
1264 \\
\text { br, struct }\end{array}$ & $\begin{array}{c}1303 \\
1285 \\
1274 \\
1267 \\
\text { br, struct }\end{array}$ & $\begin{array}{c}1301 \\
1288 \\
1274 \\
1264 \\
\text { br, struct }\end{array}$ & 1348.8 vs & $\mathrm{v}\left(\mathrm{C}-\mathrm{CF}_{3}\right) / \delta \mathrm{OH}$ \\
\hline $1290 \mathrm{~m}$ & $\begin{array}{c}1304 \\
1291 \mathrm{~m}, \mathrm{br}\end{array}$ & $1290 \mathrm{w}$ & $1294 \mathrm{w}$ & $1292^{d} \mathrm{~m}$ & 1327.7 vvs & $v\left(C-\mathrm{CF}_{3}\right) / \delta \mathrm{OH} / \delta \mathrm{C}_{\mathrm{sp} 2} \mathrm{H}$ \\
\hline $1216 \mathrm{sh}$ & $1217 \mathrm{sh}$ & $1213 \mathrm{~s}$ & $1224.7 \mathrm{~s}$ & $\begin{array}{l}1223.5 \mathrm{~s} \\
1221.5 \mathrm{~s}\end{array}$ & $1279.0 \mathrm{~s}$ & $\mathrm{vCF}_{3}(\mathrm{as}) \mathrm{a}^{\prime} / \delta \mathrm{C}_{\mathrm{sp2} 2} \mathrm{H}$ \\
\hline $\begin{array}{l}1211 \mathrm{~s} \\
1201 \mathrm{~s}\end{array}$ & $\begin{array}{l}1212 \mathrm{~s} \\
1201 \mathrm{~s}\end{array}$ & 1208 vs & $\begin{array}{l}1219^{d} \mathrm{~m} \\
1209 \mathrm{~m}\end{array}$ & $1210 \mathrm{~s}, \mathrm{br}$ & 1264.0 vs & $\mathrm{vCF}_{3}$ (as) a' \\
\hline $1204 \mathrm{~m}$ & $1210 \mathrm{~m}, \mathrm{sh}$ & & $1205 w$ & $1204 \mathrm{w}$ & & \\
\hline $1197 \mathrm{~m}$ & $1198 \mathrm{~m}$ & $1199 \mathrm{~m}$ & $1197.5 \mathrm{~m}$ & $1198 \mathrm{~m}$ & $1225.1 \mathrm{~s}$ & $\delta \mathrm{C}_{\mathrm{sp} 2} \mathrm{H}$ \\
\hline 1168 vs & 1173 vs & $1175 \mathrm{w}$ & $1184.5 \mathrm{~m}$ & $1181 \mathrm{~m}$ & 1239.3 vs & $\mathrm{vCF}_{3}$ (as) a" \\
\hline & $1164 \mathrm{w}$ & $1166 \mathrm{w}$ & & $1173 w$ & & \\
\hline $1160 \mathrm{~m}$ & $1158 \mathrm{~m}$ & $1156 \mathrm{w}$ & $1160.5 \mathrm{~m}$ & $1160 \mathrm{~m}$ & 1213.8 vs & $\mathrm{vCF}_{3}$ (as) a" \\
\hline 1112 & $1112 \mathrm{~m}$ & $1110^{f}$ & $1111.5^{f}$ & $1111^{f}$ & $1147.7 \mathrm{~m}$ & $\delta \mathrm{C}_{\mathrm{sp} 2} \mathrm{H}$ \\
\hline $1107.4 \mathrm{~s}$ & $1109 \mathrm{~m}$ & 1110 vs & $\begin{array}{l}1110.5 \mathrm{~s} \\
1111.5 \mathrm{~s}\end{array}$ & $1110 \mathrm{~s}$ & $1137.6 \mathrm{~s}$ & $\delta \mathrm{C}_{\mathrm{sp} 2} \mathrm{H} / \mathrm{v}\left(\mathrm{CO}-\mathrm{C}_{\mathrm{sp} 2} \mathrm{H}\right) / \mathrm{v}\left(\mathrm{CF}_{3}\right)$ \\
\hline 1034 vvvw & $1036 \mathrm{vw}$ & 1036 vw & $1039 \mathrm{vw}$ & $1037 \mathrm{vw}$ & $1063.7 \mathrm{vw}$ & $\rho \mathrm{CH}_{3} \mathrm{a}^{\prime \prime}$ \\
\hline $1024 \mathrm{vw}$ & 1027 vw & $1024.4 \mathrm{vw}$ & & 1027 vw & $1052.0 \mathrm{vw}$ & $\rho \mathrm{CH}_{3} \mathrm{a}^{\prime \prime}$ \\
\hline
\end{tabular}




\begin{tabular}{|c|c|c|c|c|c|c|}
\hline 1009 vw & $1010 \mathrm{vw}$ & 1009 vw & $1012 \mathrm{vw}$ & $1010 \mathrm{vw}$ & $1033.1 \mathrm{vw}$ & $\rho \mathrm{CH}_{3} \mathrm{a}^{\prime}$ \\
\hline 986 vw & $988 \mathrm{vw}$ & 987 vvw & 988 vvw & 988 vw & $1004.9 \mathrm{w}$ & $\Delta / \rho \mathrm{CH}_{3} \mathrm{a}^{\prime}$ \\
\hline 941.5 vw & 943 vw & 944 vw & $\begin{array}{l}942.5 \mathrm{vw} \\
944.5 \mathrm{vw}\end{array}$ & $\begin{array}{c}942 \mathrm{vw} \\
944.5 \mathrm{vw}\end{array}$ & $967.5 \mathrm{vw}$ & $\Delta$ \\
\hline 894 vw & $898 w$ & 898 vw & $898^{d}$ vvw & $895^{d}$ vvw & $921.2 \mathrm{~m}$ & YOH \\
\hline $\begin{array}{l}915 \text { vw } \\
875 \text { vvw }\end{array}$ & $\begin{array}{c}916 \mathrm{vw} \\
887 \mathrm{vw} \\
878 \mathrm{vvw}\end{array}$ & $\begin{array}{l}934 \text { vw } \\
913 \text { vw } \\
898 \text { vw }\end{array}$ & $\begin{array}{c}915 \mathrm{vw} \\
884.0 \mathrm{vw}\end{array}$ & $\begin{array}{c}921 \mathrm{vw} \\
905 \mathrm{vvw} \\
882.5 \mathrm{vw}\end{array}$ & $904.0 \mathrm{~m}$ & $\mathrm{YOH}$ \\
\hline $861 \mathrm{w}$ & $861 \mathrm{w}$ & $862.1 \mathrm{~m}$ & $863 \mathrm{~m}$ & $862.5 \mathrm{~m}$ & $889.6 \mathrm{w}$ & $\mathrm{v}\left(\mathrm{CH}_{3}-\mathrm{C}\right) / \mathrm{v}\left(\mathrm{C}-\mathrm{CF}_{3}\right)$ \\
\hline 845 vw & 846 vw & & & & $872.7^{d}$ vw & $\mathrm{v}\left(\mathrm{CH}_{3}-\mathrm{C}\right) / \mathrm{v}\left(\mathrm{C}-\mathrm{CF}_{3}\right)$ \\
\hline $\begin{array}{l}803 \mathrm{vw} \\
800.0 \mathrm{w}\end{array}$ & $\begin{array}{l}802.5 \mathrm{w} \\
800 \mathrm{vw}\end{array}$ & 801 vvw & & $\begin{array}{l}801.5 \mathrm{vw} \\
806.0 \mathrm{vw} \\
\end{array}$ & $833.7 \mathrm{~m}$ & $\gamma \mathrm{C}_{\mathrm{sp2}} \mathrm{H}$ \\
\hline $791 \mathrm{w}$ & $\begin{array}{l}793 w \\
792 w\end{array}$ & $791 \mathrm{~m}$ & $\begin{array}{c}794.3 \mathrm{w} \\
790.2 \mathrm{vw}\end{array}$ & $793.5 \mathrm{~m}$ & $813.7 w$ & $\gamma \mathrm{C}_{\mathrm{sp} 2} \mathrm{H}$ \\
\hline 759 vw & $762 \mathrm{vw}$ & $761 \mathrm{vw}$ & $763.5 \mathrm{vw}$ & $763 w$ & $775.0 \mathrm{w}$ & $\Gamma / \gamma \mathrm{C}_{\mathrm{sp} 2} \mathrm{H}$ \\
\hline $730 w$ & $729.5 \mathrm{w}$ & $729.5 \mathrm{w}$ & $731.3 \mathrm{~m}$ & $730.5 \mathrm{w}$ & $749.4 \mathrm{~m}$ & $\delta \mathrm{CF}_{3}$ (umbrella) \\
\hline \multirow[t]{2}{*}{$720 w$} & $720 w$ & 720 vvw & & & $736.1 \mathrm{w}$ & $\delta \mathrm{CF}_{3}$ (umbrella) \\
\hline & $575 \mathrm{~m}$ & & & & $584.7 \mathrm{~m}$ & $\delta\left(\mathrm{CH}_{3}-\mathrm{C}-\mathrm{O}\right)$ \\
\hline
\end{tabular}

${ }^{a}$ s-strong, m-medium, w- weak, v-very, sh-shoulder, br-broad, struc-structured; C-H stretching modes only observed in concentrated samples

${ }^{\mathrm{b}}$ vs $>200 ; \mathrm{s}>100 ; \mathrm{m}>40 ; \mathrm{w}>10 ; \mathrm{vw}<10$ in $\mathrm{km} / \mathrm{mol}$

${ }^{\mathrm{c}}$ same notations and descriptions as in Tables 2 and 3

dentative

${ }^{\mathrm{e}}$ from fig.6

${ }^{\mathrm{f}} \mathrm{CCC}(\mathrm{OH})$ not visible in $\mathrm{Ar}, \mathrm{Ne}$ and $\mathrm{pH}_{2}$ samples, possibly below the intense band of $\mathrm{CCC}(\mathrm{CO})$

b) Temperature, annealing, irradiation effects

Theoretical calculations show that TFacac has vibrational modes of very low frequencies, especially the $\mathrm{CCC}(\mathrm{CO})$ isomer which is the most stable one. The lowest mode of $\mathrm{CCC}(\mathrm{CO})$ is predicted in the $10-20 \mathrm{~cm}^{-1}$ range $\left(\mathrm{CF}_{3}\right.$ torsion) and should be more and more populated with a temperature increase. On the other hand, a very low energy gap $\Delta \mathrm{E}_{\mathrm{ccc}}$ between both isomers is predicted. One could thus expect experimental reversible effects with temperature in the spectra due to changes of populations either between isomers, or in $\mathrm{CF}_{3}$ torsional levels, or both. In fact, no significant change is detected when the sample temperature grows, except a broadening and slight frequency shifts of several bands, even in Ar for which a temperature of $30 \mathrm{~K}$ is reached without damage of the matrix. No reversible temperature effects were clearly detected. Such effects were only weakly observed in $p \mathrm{H}_{2}$, in the 2.8-4.5K temperature range, and are difficult to understand at this stage. A more detailed study will be conducted in $p \mathrm{H}_{2}$, beyond the scope of the present work.

However, irreversible temperature effects are detected in the annealing process. Annealing induces spectral modifications obviously correlated to a change in the populations of the two CCC isomers. This result is highly host dependent. As expected, annealing induces slight changes in the infrared bands related to site effects in all matrices. What is surprising, though, is that in $\mathrm{N}_{2}$ and $\mathrm{CO}, \mathrm{CCC}(\mathrm{OH})$ bands increase in intensity after annealing, and those of $\mathrm{CCC}(\mathrm{CO})$ decrease. The case of $\mathrm{N}_{2}$ matrix is shown in Figure 5. In $\mathrm{Ar}$, the $\mathrm{CCC}(\mathrm{OH}) / \mathrm{CCC}(\mathrm{CO})$ ratio $\left(\mathrm{R}_{21}\right)$ does not increase or decrease upon annealing. In $\mathrm{Ne}$ and $p \mathrm{H}_{2}$, a weak increase of $\mathrm{R}_{21}$ can be observed upon annealing, but it can be correlated to the diffusion of water impurities in the matrix during the annealing process. Platakyte et al. ${ }^{23}$ have shown that the $\mathrm{CCC}(\mathrm{OH})$ form is stabilized in the TFacac-water complex. Consequently, the formation of complexes with water upon annealing can lead to an increase of the $\mathrm{CCC}(\mathrm{OH})$ form. Unfortunately, the annealing processes were only conducted in $\mathrm{Ne}$ and $\mathrm{pH}_{2}$ samples containing 
traces of water impurities. In contrast, no traces of water were detected in the $\mathrm{N}_{2}$ and $\mathrm{CO}$ samples.

UV irradiation of various matrices $\left(p \mathrm{H}_{2}, \mathrm{Ne}, \mathrm{Ar}, \mathrm{N}_{2}\right)$ doped with TFacac was performed, and open enol conformers of $\mathbf{1}$ and $\mathbf{2}$ were formed in situ in the samples, as described in Ar in ref. 22. The results will be reported in a forthcoming publication. We used sequences of UV irradiations at different wavelengths to selectively produce the open conformers and come back to the chelated form (CCC), similarly to the case of 2-chloromalonaldehyde. ${ }^{37}$ At the end of this irradiation process, the $\mathrm{CCC}(\mathrm{CO})$ form is largely prevailing.

This effect is clearly detected in $\mathrm{N}_{2}$ matrices because of the larger $\mathrm{CCC}(\mathrm{OH})$ concentration at deposition. After annealing of the irradiated sample, once again, the amount of $\mathrm{CCC}(\mathrm{OH})$ increases. Figure 5 shows the effects of irradiation and annealing in nitrogen matrices in two representative spectral ranges, one including the isolated band of $\mathrm{CCC}(\mathrm{OH})$ about $1360 \mathrm{~cm}^{-1}$ (left panel) and the other including the out-of-plane $\mathrm{CH}$ bending mode $\left(\gamma \mathrm{C}_{\mathrm{sp} 2} \mathrm{H}\right)$ of both isomers (right panel). The whole spectra are shown in SI, Figure S5.

As shown in Figure 5, the irradiation effect $((\mathbf{d})$-(c)) is observed more easily than the annealing effect ((b)-(a) and (e)-(c)) and was essential to distinguish one isomer from the other in the congested parts of the spectra.
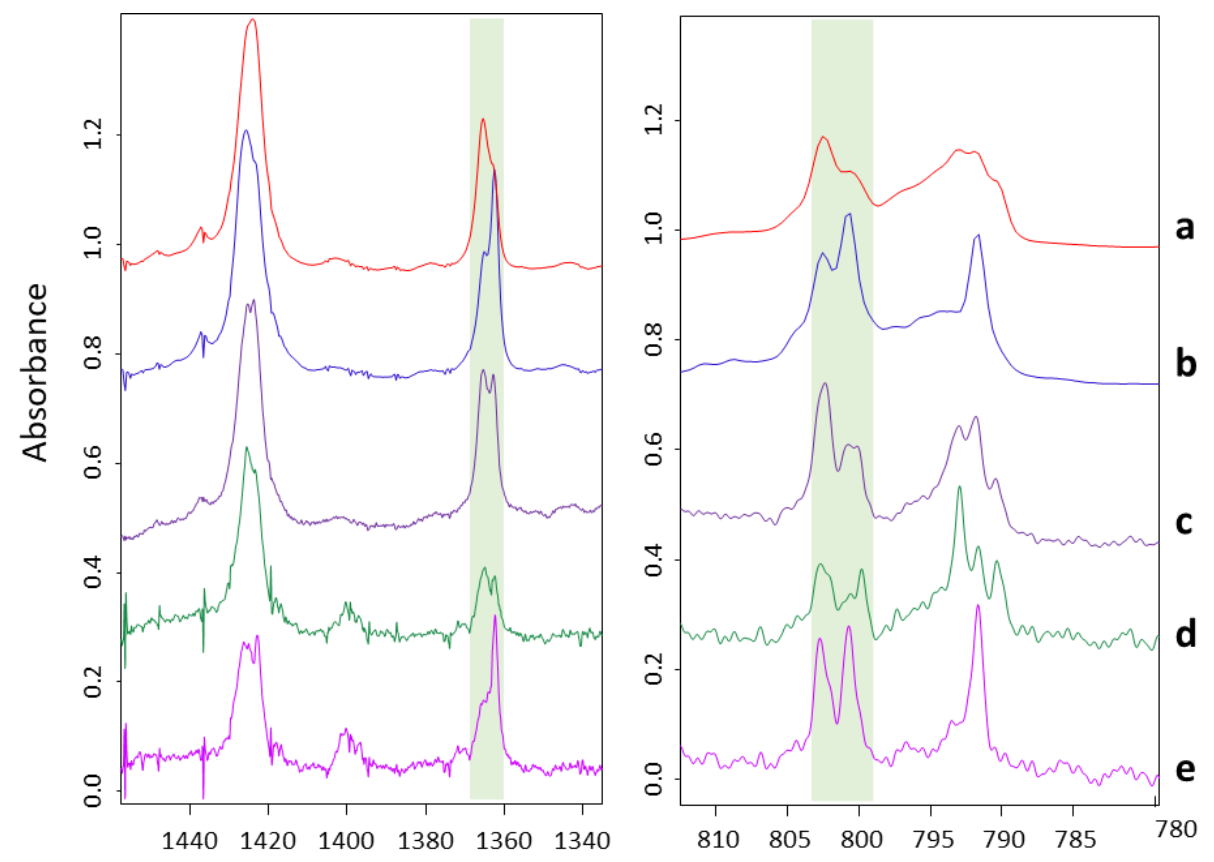

Wavenumber, $\mathrm{cm}^{-1}$

Figure 5: Spectra of trifluoroacetylacetone in nitrogen matrix, two different samples: first sample (a) before (red) and (b) after annealing (blue); second sample (c) as deposited (violet), (d) after successive UV irradiation [280 $\mathrm{nm}$ during $75 \mathrm{~min}$, followed by $225 \mathrm{~nm}$ during $35 \mathrm{~min}$ ] (green), (e) after successive UV irradiation and annealing (purple). Green vertical strips highlight $\mathrm{CCC}(\mathrm{OH})$ bands. Spectra (a) to (d) are vertically shifted for better visibility. Annealing increases the $\mathrm{CCC}(\mathrm{OH}) / \mathrm{CCC}(\mathrm{CO})$ ratio, irradiation decreases it. 
c) Assignments in the $1350-1150 \mathrm{~cm}^{-1}$ spectral range

As mentioned in part a), this spectral range is especially puzzling with broad bands and much more bands than theoretically predicted. Thanks to the results in nitrogen showing that $R_{21}=[\mathrm{CCC}(\mathrm{OH})] /[\mathrm{CCC}(\mathrm{CO})]$ increases after annealing and decreases after a specific cycle of UV irradiations, spectra of $\mathrm{CCC}(\mathrm{CO})$ and $\mathrm{CCC}(\mathrm{OH})$ can be extracted in that specific matrix. Parts of the spectral range under study are shown in Figure 6 (the whole spectra are shown in Figure S6 in SI), compared to the IR and Raman spectra of as deposited samples.

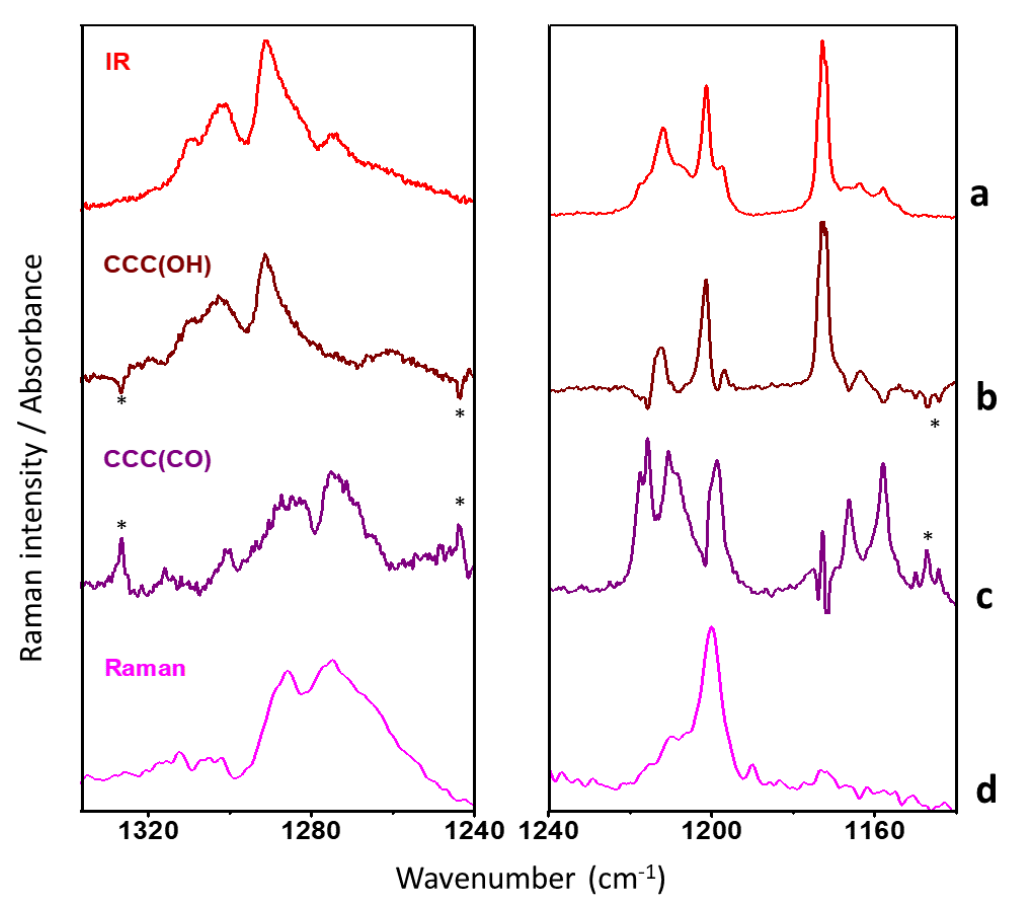

Figure 6: Parts of the spectra of TFacac in nitrogen matrix. (a) IR spectrum, (d) Raman spectrum of asdeposited samples, and IR spectra of (b) $\mathrm{CCC}(\mathrm{OH})$ and $(\mathbf{c}) \mathrm{CCC}(\mathrm{CO})$ extracted from IR spectra recorded before and after irradiation, and before and after annealing. (*: bands belonging to other isomers formed in the UV irradiation, cf manuscript in preparation: Gutiérrez-Quintanilla, A.; Chevalier, M.; Platakyte, R.; Ceponkus, J.; Crépin, C. "Open Enol Isomers of Trifluoroacetylacetone and Hexafluoroacetylacetone").

The left panel of Figure 6 shows the spectral range corresponding to a mode involving the in-plane bending of the $\mathrm{OH}$ group. This mode appears as a broad and structured band. The $\mathrm{CCC}(\mathrm{CO})$ extracted spectrum is very similar to the Raman spectrum, in agreement with the fact that this mode has a very low Raman activity in the $\mathrm{CCC}(\mathrm{OH})$ isomer. In contrast, the IR spectrum reflects mainly the spectrum of $\mathrm{CCC}(\mathrm{OH})$ in agreement with the larger IR intensity predicted in $\mathrm{CCC}(\mathrm{OH})$ than in $\mathrm{CCC}(\mathrm{CO})$.

From the right panel of Figure 6, one can deduce that three bands belong to $\mathrm{CCC}(\mathrm{OH})$ and five bands to $\mathrm{CCC}(\mathrm{CO})$ in the most puzzling part of the spectra, whereas, from calculations, only two modes of $\mathrm{CCC}(\mathrm{OH})$ and three of $\mathrm{CCC}(\mathrm{CO})$ have high IR intensity in this range. Additional bands could appear with a high intensity because of possible Fermi resonances (for example between stretching and overtones of bending modes in the $\mathrm{CF}_{3}$ groups), explaining a strong matrix effect on their frequencies. In $\mathrm{N}_{2}$, the IR spectrum is dominated by the strong $\mathrm{CCC}(\mathrm{OH})$ bands in this spectral range (see Figures $6 a$ and $6 \mathrm{~b}$ ). The band observed in Raman (Figure $6 \mathrm{~d}$ ) belongs to $\mathrm{CCC}(\mathrm{CO})$, because its 
relative intensity does not depend on the host (see Figure 3). It corresponds to the only mode in this range not involving $\mathrm{C}-\mathrm{F}$ stretching.

Almost all the bands of TFacac in $\mathrm{N}_{2}$ are thus assigned. The assignments are illustrated in SI, Figure S7, where IR and Raman experimental spectra compare with calculated spectra. The case of CO matrix is very similar to $\mathrm{N}_{2}$, with an IR spectrum dominated by the $\mathrm{CCC}(\mathrm{OH})$ spectrum in the 1350 $1150 \mathrm{~cm}^{-1}$ spectral range. Assignments in the other matrices are deduced from this study and reported in Table 5. One can remark that the intense doublet at $1212-1201 \mathrm{~cm}^{-1}$ in $\mathrm{N}_{2}$ appears as either a doublet or a single band depending on the matrix (e.g. one band at $1208 \mathrm{~cm}^{-1}$ in Ar). Minor bands are recorded between the strong bands in all matrices (with a matrix dependence), probably coming from vibrational resonances. They will not be discussed here. Bands of $\mathrm{CCC}(\mathrm{OH})$ in this spectral range are observed in all matrices: their high IR intensity allows their detection even in the case of traces of $\mathrm{CCC}(\mathrm{OH})$.

\section{Discussion}

\section{1) Comparison with previous works}

According to our calculations (Theoretical Results section), the energy gap between both CCC isomers $\left(\Delta \mathrm{E}_{\mathrm{cCC}}\right)$ is $1.0,2.0$ or $4.1 \mathrm{~kJ} \mathrm{~mol}^{-1}$ depending on the method (MP2, DFT/M06-2x and DFT/B3LYP-D3 respectively). These values are in good agreement with previous predictions. ${ }^{12-14,22}$ The most important consequence of such results is that the amount of $\mathrm{CCC}(\mathrm{OH})$ in equilibrium with $\mathrm{CCC}(\mathrm{CO})$ in the gas phase at room temperature should be substantial and this second isomer should appear in the spectra of TFacac in the gas phase whilst it has never been reported.

Infrared bands are broad in the gas phase spectra and $\mathrm{CCC}(\mathrm{OH})$ vs $\mathrm{CCC}(\mathrm{CO})$ bands can be difficult to distinguish because theoretical calculations predict often close frequencies. However, our experimental results point out a $\mathrm{CCC}(\mathrm{OH})$ band quite far from $\mathrm{CCC}(\mathrm{CO})$ bands, in the $1360-1370 \mathrm{~cm}^{-1}$ range. This band is effectively well observed in the gas phase infrared spectra at $1370 \mathrm{~cm}^{-1} .13,20,21$ Taking into account a large amount of $\mathrm{CCC}(\mathrm{OH})$ in the gas phase samples, the band at $1660 \mathrm{~cm}^{-1}$ must also be assigned to $\mathrm{CCC}(\mathrm{OH})$, together with the band at $1187 \mathrm{~cm}^{-1}$ mentioned in ref. 21 . Other bands should include a mixture of both isomers. In particular, bands of the gas phase spectrum measured around $1300 \mathrm{~cm}^{-1}$, at $1211(1207) \mathrm{cm}^{-1}$ and at $1187(1175) \mathrm{cm}^{-1}$ in ref. 21 (13 respectively) should reflect $\mathrm{CCC}(\mathrm{OH})$ bands rather than $\mathrm{CCC}(\mathrm{CO})$ considering the relative intensities of $\mathrm{IR}$ bands in this spectral range highlighted by the present study. The band $\sim 1370 \mathrm{~cm}^{-1}$ was also detected in the spectra recorded in the liquid phase and the neat product. It was detected in Ar matrix (at $1363 \mathrm{~cm}^{-1}$ ) and assigned to $\mathrm{CCC}(\mathrm{CO})$ in the study of Minoura et al.. ${ }^{22}$ The comparison between their assignment and Table 5 shows few new assignments of strong bands (i.e. at 1208 and $1176 \mathrm{~cm}^{-1}$ ). CCC(OH) was obviously wrongly neglected in the previous spectroscopic studies.

2) Stabilities and relative amounts of the two isomers

At $20 \mathrm{~K}$ or less, a Boltzmann distribution of both isomers gives a negligible amount of $\mathrm{CCC}(\mathrm{OH})$, whatever the method used to evaluate $\Delta \mathrm{E}_{\mathrm{ccc}}$. A kinetic trapping of the gas phase mixture in the cryogenic matrix should preserve a quantity of $\mathrm{CCC}(\mathrm{OH})$ large enough to observe this isomer. The spectra in water free Ne samples, showing a negligible amount of $\mathrm{CCC}(\mathrm{OH})$, are in agreement with the expected Boltzmann distribution at low temperature, far from that at room temperature. A large 
predominance of $\mathrm{CCC}(\mathrm{CO})$ in Ne matrices indicates that a fast $\mathrm{CCC}(\mathrm{OH}) \rightarrow \mathrm{CCC}(\mathrm{CO})$ isomerization occurs in the deposition process and/or in the matrix. The $\mathrm{CCC}(\mathrm{OH})$ isomer has not been observed in the FT-MW studies in supersonic jet. ${ }^{19}$ The possibility of conformational relaxation involving a proton transfer was suggested to explain the absence of this isomer. Because this experiment was performed with helium as carrier gas, the probability of conformational relaxation is drastically reduced unless there is a very small barrier. Experiment ${ }^{19}$ and theoretical calculations (see Theoretical Results section) highlight a very low rotational barrier in the $\mathrm{CF}_{3}$ group of $\mathrm{CCC}(\mathrm{CO})$. Therefore, the formation of $\mathrm{CCC}(\mathrm{CO})$ from $\mathrm{CCC}(\mathrm{OH})$ implies almost only motions of hydrogen atoms $\left(\mathrm{CH}_{3}\right.$ rotation and $\mathrm{H}$ transfer in the $\mathrm{H}$ bond) which could take place with tunneling at low temperature.

Except in $\mathrm{Ne}, \mathrm{CCC}(\mathrm{OH})$ is present in significant amounts in all the probed hosts, even in absence of water traces. Table 6 summarizes the $R_{21}$ values $\left(R_{21}=C C C(O H) / C C C(C O)\right)$ deduced from IR spectra in as-deposited samples. Even if the results reflect qualitative tendencies more than quantitative ratios, $R_{21}$ is clearly matrix dependent and increases from $\mathrm{Ne}$ to $\mathrm{Ar}$ to $\mathrm{N}_{2}$ to CO. From Raman results (Figure $3), R_{21}$ is smaller in Xe than in Ar. We conclude that $\mathrm{CCC}(\mathrm{OH})$ is only weakly stabilized in rare gas matrices, in contrast with $\mathrm{N}_{2}$ or $\mathrm{CO}$ matrices. Moreover, annealing of the latter matrices induces an increase of $R_{21}$ which is puzzling. The estimations of $R_{21}$ after annealing give a predominance of the second isomer $(\mathrm{CCC}(\mathrm{OH})$ ) (see Table 6). This matrix dependent annealing effect underlines definitively the role of interactions with the environment for the relative energies of both chelated isomers. It could be due to an efficient stabilization of $\mathrm{CCC}(\mathrm{OH})$ in well-ordered $\mathrm{N}_{2}$ and $\mathrm{CO}$ lattices, with an increase of well-defined sites after annealing.

An opposite result was obtained with irradiation effects: the isomerization from open forms to chelated ones by UV irradiation favors the $\mathrm{CCC}(\mathrm{CO})$ isomer. This conclusion should help in the understanding of the isomerization process of TFacac in matrices. ${ }^{22}$

Table 6: $\mathrm{R}_{21}=\mathrm{CCC}(\mathrm{OH}) / \mathrm{CCC}(\mathrm{CO})$ values extracted from the spectroscopic results in the various probed hosts. IR bands around $800 \mathrm{~cm}^{-1}$ are used for these estimations because they are well separated and correspond to the same vibrational mode $\left(\mathrm{\gamma C}_{\mathrm{sp2} 2} \mathrm{H}\right.$, see table 5$)$. The one at $793 \mathrm{~cm}^{-1}$ belongs to $\mathrm{CCC}(\mathrm{CO})$ and the one at $802.5 \mathrm{~cm}^{-1}$ to $\mathrm{CCC}(\mathrm{OH})$; the intensity ratio is predicted at 1.19 (MP2), 1.68 (M06-2X) or 1.12 (B3LYP-D3) (see Tables 2 and 3). $R_{21}$ is calculated from integrated band areas taking into account the calculated intensities (M06-2X calculations predict these values to be 24.62 for $\mathrm{CCC}(\mathrm{CO})$ and 41.34 for $\mathrm{CCC}(\mathrm{OH})$ band).

\begin{tabular}{|l|c|c|c|}
\hline & As deposited & After annealing & After irradiation \\
\hline $\mathrm{Ne}$ & $\leq 0.007$ & & - \\
\hline $\mathrm{Ar}$ & $\leq 0.01$ & $\leq 0.01$ & \\
\hline $\mathrm{pH}_{2}{ }^{*}$ & $\leq 0.08$ & & \\
\hline $\mathrm{N}_{2}$ & $0.42 \pm 0.08$ & $1.2 \pm 0.3$ & $0.35 \pm 0.01$ \\
\hline $\mathrm{CO}$ & $0.75 \pm 0.2$ & $1.45 \pm 0.3$ & - \\
\hline
\end{tabular}

* samples with water impurities

The dependence of $R_{21}$ ratio on the matrix host and on the experimental conditions indicates that one cannot deduce an experimental estimation of $\Delta \mathrm{E}_{\mathrm{ccc}}$ in the gas phase from the results in matrices.

3) Comparison with theoretical predictions

The present experimental results allow a new investigation of the comparison with calculations in terms of mode frequency predictions. We have used three different calculation methods as 
described above (Theoretical results Part) to obtain wavenumbers of vibrational modes of both isomers. Combined use of infrared and Raman spectroscopy allowed us to experimentally observe more vibrational modes than in the case of only infrared spectroscopy, especially in low wavenumber region. As nitrogen matrix exhibits the clearest experimental bands, we choose the results in this matrix to detail the comparison with the calculated ones. Experimental data in $\mathrm{Ne}$ and $\mathrm{pH}_{2}$ are similarly analyzed in Part V. of SI. Comparison of experimental and theoretical wavenumbers allows us to estimate the optimal scaling factor for the three methods in the main spectral range of interest $\left(700-1500 \mathrm{~cm}^{-1}\right)$. The smallest scaling factor is obtained for B3LYP-D3 method -0.985 , and it is almost the same for M06-2X and for MP2 (0.971 and 0.970 respectively). In order to check the consistency of the scaling factor for different vibration modes we have calculated the ratio between experimental and scaled calculated values. Obviously if the scaling factor works for all the modes the same this ratio should be equal to 1 . These ratios are presented in Figure 7 (similar plots are presented in Figure $\mathrm{S} 8$ in $\mathrm{SI}$ concerning results in $\mathrm{Ne}$ and $p \mathrm{H}_{2}$ ): the deviation from 1 is weak in the fingerprint region (range on white background in Figure 7). However, close looks reveal that two methods MP2 and M06-2X are more consistent with each other while B3LYP-D3 shows somewhat large dispersion of the deviations for different modes. As expected, $\mathrm{C}-\mathrm{H}$ stretching and low frequency modes are not well reproduced when the scaling factor optimized in the $700-1500 \mathrm{~cm}^{-1}$ range is used.

Of particular interest are the modes where discrepancies between the theoretical methods are the greatest in the fingerprint region. That is modes involving $\mathrm{OH}$ bending (numbers 13 and 21 in $\mathrm{CCC}(\mathrm{CO}), 13$ and 20 in $\mathrm{CCC}(\mathrm{OH})$ ) underlined by red vertical strips in Figure 7 , and modes involving $\mathrm{CF}$ stretching in the $\mathrm{CF}_{3}$ group (numbers 14 and 16 in $\mathrm{CCC}(\mathrm{CO})$ and 15 and 16 in $\mathrm{CCC}(\mathrm{OH})$ ) underlined by green vertical strips in Figure 7 - see Tables 2 and 3 for numbering. $\mathrm{CF}_{3}$ group modes are in the range which is very difficult to assign in experimental spectrum, different methods even change the ordering of the modes. Experimentally we also observe more than one band for each of these modes. Excluding these two kinds of modes, the deviation from 1 in the region of interest is below \pm 0.02 for all three methods. Interestingly, CF stretching modes are well reproduced with MP2 (black squares in green zones close to 1 in Figure 7), while $\mathrm{OH}$ bending modes are less accurate. Taking into account all the modes, M06-2X results show the best agreement with the experiments, slightly better than MP2, and much better than B3LYP-D3. The same conclusions are deduced from the data of both isomers (see Figure 7) and the data analyzed in $\mathrm{Ne}$ and $\mathrm{pH}_{2}$ (see SI: part $\mathrm{V}$ and Figure $\mathrm{S} 8$ ). It is worth noting that the modes involving $\mathrm{CF}_{3}$ group vibration are better reproduced using M06-2X than B3LYP functional as pointed out in previous works. ${ }^{30}$ 

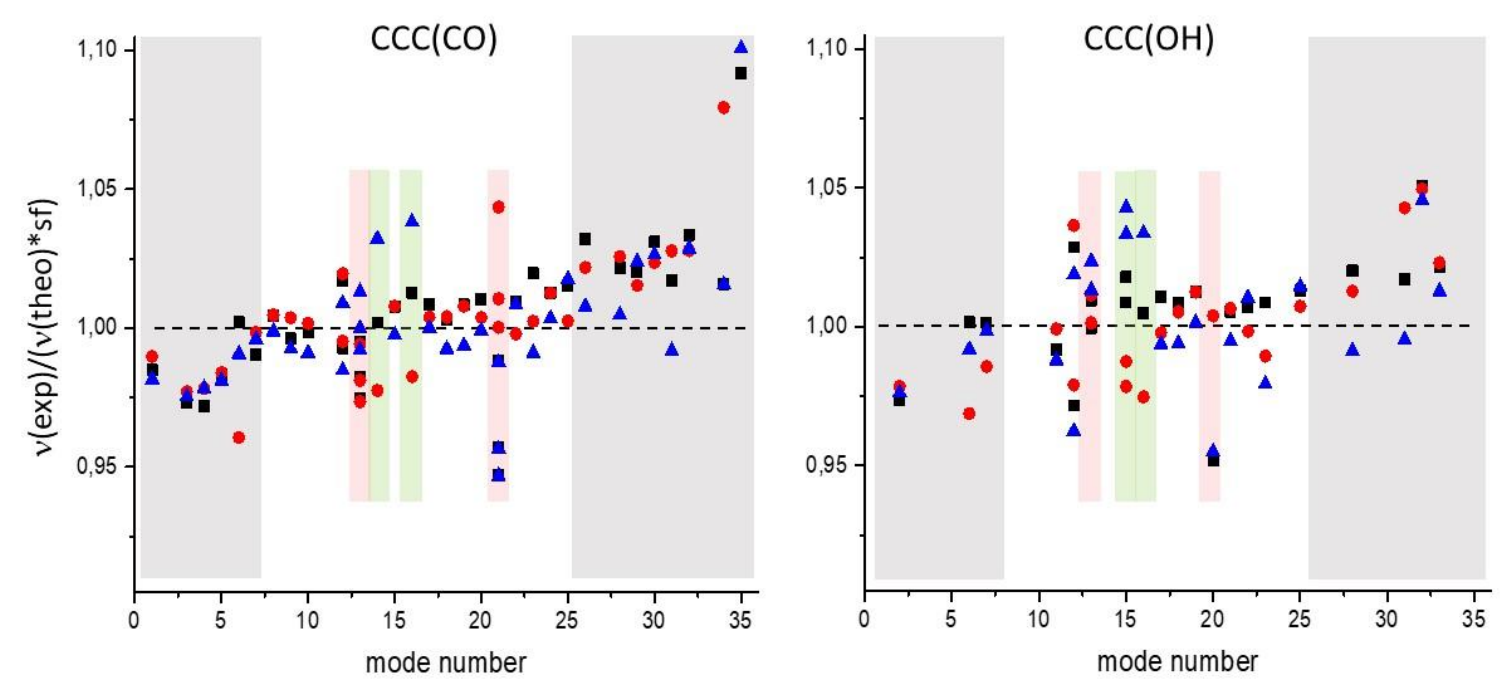

Figure 7: Ratios between the experimental frequencies and the scaled theoretical frequencies $\left[v(\exp ) /\left(v(\text { theo })^{*} \mathrm{sf}\right)\right]$ for TFacac modes in nitrogen matrices; $\mathrm{CCC}(\mathrm{CO})$ left panel, $\mathrm{CCC}(\mathrm{OH})$ right panel; black squares MP2 (scaling factor $(s f)=0.970)$, red circles M06-2X ( $s f=0.971$ ), blue triangles B3LYP ( $\mathrm{s}=0.985$ ); modes involving $\mathrm{OH}$ bending in red vertical strips (modes 13 and 21 in $\mathrm{CCC}(\mathrm{CO}), 13$ and 20 in $\mathrm{CCC}(\mathrm{OH})$ ) and $\mathrm{CF}_{3}$ modes in green vertical strips (modes 14 and 16 in $\mathrm{CCC}(\mathrm{CO}), 15$ and 16 in $\mathrm{CCC}(\mathrm{OH})$; modes excluded in the estimation of sf in grey background.

The fewer number of modes experimentally explored in $\mathrm{CCC}(\mathrm{OH})$ than in $\mathrm{CCC}(\mathrm{CO})$ does not allow us to conclude on the relative accuracy of the theoretical predictions in both isomers, but the present data highlight exactly the same tendencies in both isomers. The scaling factors were optimized separately for each isomer (see Table S2 in SI). The results allow us to use the same scaling factors, slightly matrix dependent, for both isomers, as was done in Figure 7. This analysis reinforces the new assignments to $\mathrm{CCC}(\mathrm{OH})$.

\section{4) H-bond characteristics}

Previous studies in the $\beta$-diketone family have shown that the intramolecular hydrogen bond strength changes as follows: hexafluoroacetylacetone $<$ trifluoroacetylacetone $<$ acetylacetone. ${ }^{14,21,24}$ The present results allow a detailed study of the two CCC isomers of TFacac.

In intramolecular hydrogen bonded systems, the coordinates involved in the $\mathrm{H}$ bond are the most affected. The shorter the $\mathrm{O} \cdots \mathrm{O}$ distance and larger the $\mathrm{O}-\mathrm{H} \cdots \mathrm{O}$ angle, the stronger the $\mathrm{H}$-bond. ${ }^{2}$ These parameters, reported in Table 7 from theoretical calculations, show that, under these indicators, the $\mathrm{H}$-bond is stronger in $\mathrm{CCC}(\mathrm{OH})$ than in $\mathrm{CCC}(\mathrm{CO})$. The $\mathrm{H}$-bond in $\beta$-dicarbonyl molecules has a cooperative character, being classified as a Resonance-Assisted Hydrogen Bond (RAHB), due to the delocalization of $\pi$ electrons in the HOCCCO pseudo-ring. In order to quantitatively compare the effect of $\pi$ delocalization, one can calculate the parameter $Q$ (known as the coordinate of $\pi$ bond delocalization) defined by: $Q=(d[C-O]-d[C=O])+(d[C-C]-d[C=C]){ }^{2}$ Smaller $Q$ means stronger $\pi$ delocalization. Values reported in Table 7 show that the effect of delocalization is more important in $\mathrm{CCC}(\mathrm{CO})$ than in $\mathrm{CCC}(\mathrm{OH})$. As $\mathrm{CCC}(\mathrm{CO})$ is found more stable than $\mathrm{CCC}(\mathrm{OH})$, the theoretical conclusion is that the effect of $\pi$-electrons delocalization is stronger than the $\mathrm{H}$ bond effect to stabilize the 
TFacac geometry. Nowroozi et al. ${ }^{14}$ had performed a theoretical study on that molecule using various theoretical methods leading to the same conclusion.

The strength of the $\mathrm{H}$-bond is also reflected in the vibrational frequencies of the $\mathrm{OH}$ stretching $(\mathrm{vOH})$ and bending modes $(\delta \mathrm{OH}$ in plane and $\gamma \mathrm{OH}$ out of plane): stronger the $\mathrm{H}$-bond is, lower the stretching frequency is and higher the bending frequencies are. In most of the cases, there are no vibrational modes corresponding to "pure" $\mathrm{OH}$ stretching or bending. However, very similar modes linked to these motions exist in both isomers. The corresponding theoretical values are reported in Table 7. It is difficult to assign $\mathrm{\delta OH}$ mode to only one band, especially in $\mathrm{CCC}(\mathrm{OH})$. However, the global theoretical estimations of frequencies show that according to these indicators the $\mathrm{H}$-bond is stronger in $\mathrm{CCC}(\mathrm{OH})$ than in $\mathrm{CCC}(\mathrm{CO})$, in agreement with the calculated structures.

The $\mathrm{OH}$ stretching mode is not detected in our experimental spectra, because of a too large bandwidth which prevents extracting it from the background. As mentioned previously, the in-plane $\mathrm{OH}$ bending motion is involved in several modes in both isomers. Theoretical modes showing a significant implication of this motion are reported in Table 7 together with the experimental values assigned to these modes in Table 4 and $5 . \ln \mathrm{CCC}(\mathrm{CO})$, one of these modes exhibits an $\mathrm{OH}$-bending in phase with the $\mathrm{CC}$ and $\mathrm{CO}$ stretches of the pseudo-ring facilitating the $\mathrm{H}$ transfer: it corresponds to the broad and structured band around $1280 \mathrm{~cm}^{-1}$. This broad feature is blue-shifted in $\mathrm{CCC}(\mathrm{OH})$ compared to the $\mathrm{CCC}(\mathrm{CO})$ mode involving $\mathrm{\delta OH}$ (see Figure 6, left panel), which seems to confirm a stronger $\mathrm{H}$-bond in $\mathrm{CCC}(\mathrm{OH})$. The well-defined band around $1620 \mathrm{~cm}^{-1}$ involves $\delta \mathrm{OH}$ and is also blueshifted in $\mathrm{CCC}(\mathrm{OH})$. However, it also involves double bond stretching $(\mathrm{C}=\mathrm{C}$ and $\mathrm{C}=\mathrm{O})$ which is expected to correspond to higher frequencies with a less important electronic delocalization in the pseudo-ring. The other mode involving these stretching motions is effectively at a higher frequency in $\mathrm{CCC}(\mathrm{OH})$ than in $\mathrm{CCC}(\mathrm{CO})$ (see Table 7). Unfortunately, the experimental data on the OH out-ofplane mode are not very clear, with a not well-defined band in $\mathrm{CCC}(\mathrm{CO})$. Preliminary results of temperature effects in $\mathrm{pH}_{2}$ seem to show an increase of intensity of the high frequency part of the $\gamma \mathrm{OH}(\mathrm{CCC}(\mathrm{CO}))$ structure $\left(921 \mathrm{~cm}^{-1}\right)$ and a decrease of the narrower low frequency band $\left(882.5 \mathrm{~cm}^{-1}\right)$ with an increase of temperature from $2.8 \mathrm{~K}$ to $4.5 \mathrm{~K}$. It could correspond to transitions from the lowest torsional level of $\mathrm{CF}_{3}$ (the latter, corresponding to the theoretical description) and from a higher $\mathrm{CF}_{3}$ torsional level (the former), indicating an enhancement of the $\mathrm{H}$-bond with a torsional excitation. Such an effect was observed in acetylacetone trapped in $\mathrm{pH}_{2}$ with the methyl torsion. ${ }^{39,40}$

Table 7: Geometrical parameters and vibrational frequencies related to the internal H-bond in $\mathrm{CCC}(\mathrm{CO})$ and $\mathrm{CCC}(\mathrm{OH})$ isomers of trifluoroacetylacetone

\begin{tabular}{|c|c|c|c|}
\hline & & $\mathrm{CCC}(\mathrm{CO})$ & $\mathrm{CCC}(\mathrm{OH})$ \\
\hline \multirow{3}{*}{$\begin{array}{l}d[0 \cdots 0] \quad(A ̊) \\
2 X\end{array}$} & \multirow{3}{*}{$\begin{array}{r}\text { MP2 } \\
\text { M06- } \\
\text { B3LYP-D3 }\end{array}$} & 2.56 & 2.53 \\
\hline & & 2.584 & 2.543 \\
\hline & & 2.58 & 2.55 \\
\hline \multirow{3}{*}{$A(O-H \cdots O)\left({ }^{\circ}\right)$} & \multirow{3}{*}{$\begin{array}{l}\text { MP2 } \\
\text { M06-2X } \\
\text { B3LYP-D3 }\end{array}$} & 149.1 & 149.2 \\
\hline & & 145.6 & 145.7 \\
\hline & & 146.5 & 146.7 \\
\hline \multirow{3}{*}{$Q(\AA)$} & MP2 & 0.14 & 0.17 \\
\hline & M06-2X & 0.16 & 0.20 \\
\hline & B3LYP-D3 & 0.14 & 0.18 \\
\hline \multirow{3}{*}{$\mathrm{VOH}\left(\mathrm{cm}^{-1}\right)$} & MP2 & 3213.1 & 3084.2 \\
\hline & M06-2X & 3353.4 & 3210.9 \\
\hline & B3LYP-D3 & 3205.9 & 3078.9 \\
\hline
\end{tabular}




\begin{tabular}{|c|c|c|}
\hline MP2 & $1672.6 / 1348.8$ & 1670.8/1417.9/1393.1/1331.5 \\
\hline$\delta O H\left(\mathrm{~cm}^{-1}\right)$ & $1657.7 / 1348.8$ & $1695.8 / 1406.1 / 1381.1 / 1327.7$ \\
\hline B3LYP-D3 & $1638.3 / 1304.9$ & $1650.3 / 1401.9 / 1385.1 / 1293.5$ \\
\hline Experiment in $\mathrm{Ne}$ & $1614 / 1285-1267$ & $1633 / 1367 /-/ 1294$ \\
\hline Experiment in $\mathrm{N}_{2}$ & $1607 / 1285-1275$ & $1623 / 1363 / 1313 / 1291$ \\
\hline MP2 & 955.6 & 972.5 \\
\hline$\gamma \mathrm{OH}\left(\mathrm{cm}^{-1}\right)$ & 904.0 & 921.2 \\
\hline B3LYP-D3 & 940.5 & 954.6 \\
\hline Experiment in $\mathrm{Ne}$ & $915-884$ & 899 \\
\hline Experiment in $\mathrm{N}_{2}$ & $916-878$ & 898 \\
\hline \multirow{4}{*}{$v C=C / v C=0 \quad(\mathrm{~cm}$} & 1702.6 & 1712.8 \\
\hline & $1774.5^{*}$ & 1769.0* \\
\hline & 1696.5 & 1703.3 \\
\hline & 1650 & 1666 \\
\hline Experiment in $\mathrm{N}_{2}$ & 1657 & 1664 \\
\hline
\end{tabular}

*modes with less accurate frequencies at the M06-2X level of theory, as shown in Figure 7 (mode number 6) and in previous works. ${ }^{41}$

In summary, the experiments are in agreement with the theory to highlight a stronger $\mathrm{H}$-bond in $\mathrm{CCC}(\mathrm{OH})$ and a higher $\pi$ delocalization in $\mathrm{CCC}(\mathrm{CO})$. The result of both effects is that $\mathrm{CCC}(\mathrm{CO})$ is the most stable isomer in the gas phase ${ }^{19}$ and in rare gas matrices. Some bands related to $\mathrm{OH}$ bending show complex shape and structure in the $\mathrm{CCC}(\mathrm{CO})$ isomer. The possible link with the weakly hindered $\mathrm{CF}_{3}$ rotation in that isomer is still to be elucidated.

\section{Conclusion}

TFacac is a very interesting example of an asymmetric molecule involving a RAHB for which the relative stability of the two isomers obtained via the $\mathrm{H}$ transfer depends on parameters that strengthen or weaken the internal $\mathrm{H}$-bond. The two isomers are located between acetylacetone and hexafluoroacetylacetone in terms of $\mathrm{H}$ bond strength. The present results confirm $\mathrm{CCC}(\mathrm{CO})$ as the most stable isomer, in agreement with previous studies. However, we found experimental conditions to get $\mathrm{CCC}(\mathrm{OH})$ as the most stable one by trapping the molecule in $\mathrm{CO}$ or $\mathrm{N}_{2}$ low temperature matrices. The matrix results (i) indicate that the $\mathrm{H}$-transfer occurs between both isomers at low temperature and (ii) suggest a very low energy gap between the isomers, in agreement with MP2 calculations. The energy gap in the isolated molecule seems to be small enough to be completely distorted by a very weakly intrusive environment such as nitrogen solid. The present MP2 calculations also predict a very low rotational barrier in the $\mathrm{CF}_{3}$ group of $\mathrm{CCC}(\mathrm{CO})$ with a theoretical value very close to the experimental one measured in FT-MW experiments. ${ }^{19}$

Thanks to its non-negligible amount in $\mathrm{N}_{2}$ or CO matrices, we were able to characterize the second isomer $(\mathrm{CCC}(\mathrm{OH}))$ by its vibrational pattern obtained via infrared and Raman spectroscopies. More than 20 vibrational modes of $\mathrm{CCC}(\mathrm{OH})$ were measured. Importantly, this study shows that several of these modes were wrongly assigned to $\mathrm{CCC}(\mathrm{CO})$ in previous works. Moreover, some $\mathrm{CCC}(\mathrm{OH})$ modes have infrared intensities large enough to be used to detect this isomer in samples where there are only traces of it.

The present experimental data can be used to test various functionals in DFT calculations to get a better description of $\mathrm{CF}_{3}$ modes. Our attempts with B3LYP-D3 and M06-2X functionals were very 
useful but do not lead to satisfying agreements, even if the description with M06-2X is the best in the C-F stretching mode region. MP2 vibrational predictions are as good as M06-2X (DFT) ones, C-F stretching modes are especially well predicted with MP2, but DFT/M06-2X has the advantage of a lower calculations time-consumption. Having in mind the mentioned discrepancies between theoretical methods used in this work and inability for the calculations to completely reproduce experimentally observed vibrational frequencies more detailed theoretical research employing high level theories including CCSD calculations could also be useful.

The assignment of the complex spectra formed by the intricate bands of $\mathrm{CCC}(\mathrm{CO})$ and $\mathrm{CCC}(\mathrm{OH})$ is almost complete. However, a few spectral ranges remain puzzling, especially around $1300 \mathrm{~cm}^{-1}$ where the infrared bands exhibit specific but reproducible shapes in all matrices. The effect of the almost free $\mathrm{CF}_{3}$ torsion of $\mathrm{CCC}(\mathrm{CO})$ on the vibrational spectra should be investigated. Preliminary experiments in $\mathrm{pH}_{2}$ on that point are promising.

\section{Supporting Information}

Structures of TFacac isomers; Calculated geometries of the chelated enols; Torsional barriers in $\mathrm{CCC}(\mathrm{OH})$; Correlations between mode frequencies calculated with the three methods; Spectra in nitrogen matrices: band assignments to $\mathrm{CCC}(\mathrm{CO})$ and $\mathrm{CCC}(\mathrm{OH})$; Comparison between theoretical and experimental mode frequencies.

\section{Acknowledgements}

The authors acknowledge the use of the computing center MésoLUM in Orsay. This work was supported by the RTRA Triangle de la Physique (2013-0436T REACMAQ). It benefited from the French-Lithuanian PHC GILIBERT program (42125XF and S-LZ-19-1 from RCL) and the French-Cuban PHC Carlos Finlay program (41805NA).

\section{References}

(1) Gilli, G.; Bellucci, F.; Ferretti, V.; Bertolasi, V. Evidence for Resonance-Assisted Hydrogen Bonding from Crystal-Structure Correlations on the Enol Form of the $\beta$-Diketone Fragment. $J$. Am. Chem. Soc. 1989, 111 (3), 1023-1028. https://doi.org/10.1021/ja00185a035.

(2) Gilli, G.; Gilli, P. The Nature of the Hydrogen Bond; Oxford University Press, 2009. https://doi.org/10.1093/acprof:oso/9780199558964.001.0001.

(3) Firth, D. W.; Barbara, P. F.; Trommsdorff, H. P. Matrix Induced Localization of Proton Tunneling in Malonaldehyde. Chem. Phys. 1989, 136 (2), 349-360. https://doi.org/10.1016/0301-0104(89)80058-8.

(4) Chiavassa, T.; Verlaque, P.; Pizzala, L.; Allouche, A.; Roubin, P. Experimental and Theoretical Studies of the Photoisomerization of Malonaldehyde Isolated in Rare Gas Matrices. J. Phys. Chem. 1993, 97, 5917-5925. https://doi.org/10.1021/j100124a024

(5) Nagashima, N.; Kudoh, S.; Takayanagi, M.; Nakata, M. UV-Induced Photoisomerization of Acetylacetone and Identification of Less-Stable Isomers by Low-Temperature Matrix-Isolation Infrared Spectroscopy and Density Functional Theory Calculation. J. Phys. Chem. A 2001, 105 (48), 10832-10838. https://doi.org/10.1021/jp012557m.

(6) Trivella, A.; Coussan, S.; Chiavassa, T.; Theulé, P.; Roubin, P.; Manca, C. Comparative Study of 
Structure and Photo-Induced Reactivity of Malonaldehyde and Acetylacetone Isolated in Nitrogen Matrices. Low Temp. Phys. 2006, 32 (11), 1042-1049.

https://doi.org/10.1063/1.2389011.

(7) Lozada-Garcia, R. R.; Ceponkus, J.; Chin, W.; Chevalier, M.; Crépin, C. Acetylacetone in Hydrogen Solids: IR Signatures of the Enol and Keto Tautomers and UV Induced Tautomerization. Chem. Phys. Lett. 2011, 504 (4-6), 142-147. https://doi.org/10.1016/j.cplett.2011.01.055.

(8) Gutierrez-Quintanilla, A.; Chevalier, M.; Crepin, C. Double Deuterated Acetylacetone in Neon Matrices: Infrared Spectroscopy, Photoreactivity and the Tunneling Process. Phys. Chem. Chem. Phys. 2016, 18 (30), 20713-20725. https://doi.org/10.1039/C6CP02796B.

(9) Rousselot-Pailley, P.; Sobanska, S.; Ferré, N.; Coussan, S. UV Photochemistry of Acetylacetaldehyde Trapped in Cryogenic Matrices. J. Phys. Chem. A 2020, 124 (24), 49164928. https://doi.org/10.1021/acs.jpca.0c02512.

(10) Trivella, A.; Wassermann, T. N.; Mestdagh, J. M.; Tanner, C. M.; Marinelli, F.; Roubin, P.; Coussan, S. New Insights into the Photodynamics of Acetylacetone: Isomerization and Fragmentation in Low-Temperature Matrixes. Phys. Chem. Chem. Phys. 2010, 12 (29), 8151. https://doi.org/10.1039/c0cp90051f.

(11) Lozada-García, R. R.; Ceponkus, J.; Chevalier, M.; Chin, W.; Mestdagh, J.-M.; Crépin, C. Photochemistry of Acetylacetone Isolated in Parahydrogen Matrices upon $266 \mathrm{Nm}$ Irradiation. Phys. Chem. Chem. Phys. 2012, 14 (10), 3450-3459. https://doi.org/10.1039/c2cp23913b.

(12) Buemi, G. Ab Initio DFT Study of the Hydrogen Bridges in Hexafluoro-Acetylacetone, TrifluoroAcetylacetone and Some 3-Substituted Derivatives. J. Mol. Struct. THEOCHEM 2000, 499, 2134. https://doi.org/10.1016/S0166-1280(99)00265-1.

(13) Raissi, H.; Nowroozi, A.; Roozbeh, M.; Farzad, F. Molecular Structure and Vibrational Assignment of (Trifluoroacetyl) Acetone: A Density Functional Study. J. Mol. Struct. 2006, 787 (1-3), 148-162. https://doi.org/10.1016/j.molstruc.2005.10.042.

(14) Nowroozi, A.; Roohi, H.; Sadeghi Ghoogheri, M. S.; Sheibaninia, M. The Competition between the Intramolecular Hydrogen Bond and $\pi$-Electron Delocalization in Trifluoroacetylacetone-A Theoretical Study. Int. J. Quantum Chem. 2011, 111 (3), 578-585. https://doi.org/10.1002/qua.22129.

(15) Sliznev, V. V.; Lapshina, S. B.; Girichev, G. V. Ab Initio Study of the Structure of Enolic and Ketonic Forms of $\beta$-Diketones with the General Formula $R^{\prime \prime} C O C H 2 C O R^{\prime}\left(R^{\prime}\right.$ and $R^{\prime \prime}=H, C H 3$, CF3). J. Struct. Chem. 2006, 47 (2), 220-231. https://doi.org/10.1007/s10947-006-0290-z.

(16) Isayev, O.; Gorb, L.; Leszczynski, J. Theoretical Calculations: Can Gibbs Free Energy for Intermolecular Complexes Be Predicted Efficiently and Accurately? J. Comput. Chem. 2007, 28, 1598-1609. https://doi.org/10.1002/jcc.20696.

(17) Andreassen, A. L.; Bauer, S. H. The Structures of Acetylacetone, Trifluoroacetylacetone and Trifluoroacetone. J. Mol. Struct. 1972, 12, 381-403. https://doi.org/10.1016/0022$\underline{2860(72) 87047-9}$

(18) Lazaar, K. I.; Bauer, S. H. Intramolecular Unsymmetrical OHO Bonds. Thermochemistry. J. Phys. Chem. 1983, 87 (13), 2411-2416. https://doi.org/10.1021/j100236a034

(19) Favero, L. B.; Evangelisti, L.; Velino, B.; Caminati, W. Morphing the Internal Dynamics of Acetylacetone by $\mathrm{CH} 3 \rightarrow \mathrm{CF} 3$ Substitutions. the Rotational Spectrum of Trifluoroacetylacetone. J. Phys. Chem. A 2014, 118 (24), 4243-4248. 
https://doi.org/10.1021/jp5005727.

(20) Tayyari, S. F.; Zeegers-Huyskens, T.; Wood, J. L. Spectroscopic Study of Hydrogen Bonding in the Enol Form of $\beta$-Diketones-I. Vibrational Assignment and Strength of the Bond. Spectrochim. Acta A 1979, 35 (11), 1265-1276. https://doi.org/10.1016/0584-8539(79)802081

(21) Zahedi-Tabrizi, M.; Tayyari, F.; Moosavi-Tekyeh, Z.; Jalali, A.; Tayyari, S. F. Structure and Vibrational Assignment of the Enol Form of 1,1,1-Trifluoro-2,4-Pentanedione. Spectrochim. Acta - Part A Mol. Biomol. Spectrosc. 2006, 65 (2), 387-396. https://doi.org/10.1016/j.saa.2005.11.019.

(22) Minoura, Y.; Nagashima, N.; Kudoh, S.; Nakata, M. Mechanism of UV-Induced Conformational Changes among Enol-Type Isomers of (Trifluoroacetyl)Acetone Studied by Low-Temperature Matrix-Isolation Infrared Spectroscopy and Density Functional Theory Calculation. J. Phys. Chem. A 2004, 108 (12), 2353-2362. https://doi.org/10.1021/jp031192y.

(23) Platakyte, R.; Gutiérrez-Quintanilla, A.; Sablinskas, V.; Ceponkus, J. Influence of Environment and Association with Water, to Internal Structure of Trifluoroacetylacetone. Matrix Isolation FTIR Study. Low Temp. Phys. 2019, 45 (6), 722-735. https://doi.org/10.1063/1.5103254.

(24) Gutiérrez-Quintanilla, A. Molecules and Complexes with Hydrogen Bond: Solvation and Photoreactivity in Cryogenic Matrices, PhD thesis.; Université Paris-Saclay - Université ParisSud, 2016. https://tel.archives-ouvertes.fr/tel-01686957/document

(25) Frisch, M. J.; Trucks, G. W.; Schlegel, H. B.; Scuseria, G. E.; Robb, M. A.; Cheeseman, J. R.; Scalmani, G.; Barone, V.; Petersson, G. A.; Nakatsuji, H.; Li, X.; Caricato, M.; Marenich, A. V; Bloino, J.; Janesko, B. G.; Gomperts, R.; Mennucci, B.; Hratchian, H. P.; Ortiz, J. V; Izmaylov, A. F.; Sonnenberg, J. L.; Williams-Young, D.; Ding, F.; Lipparini, F.; Egidi, F.; Goings, J.; Peng, B.; Petrone, A.; Henderson, T.; Ranasinghe, D.; Zakrzewski, V. G.; Gao, J.; Rega, N.; Zheng, G.; Liang, W.; Hada, M.; Ehara, M.; Toyota, K.; Fukuda, R.; Hasegawa, J.; Ishida, M.; Nakajima, T.; Honda, Y.; Kitao, O.; Nakai, H.; Vreven, T.; Throssell, K.; Montgomery Jr., J. A.; Peralta, J. E.; Ogliaro, F.; Bearpark, M. J.; Heyd, J. J.; Brothers, E. N.; Kudin, K. N.; Staroverov, V. N.; Keith, T. A.; Kobayashi, R.; Normand, J.; Raghavachari, K.; Rendell, A. P.; Burant, J. C.; Iyengar, S. S.; Tomasi, J.; Cossi, M.; Millam, J. M.; Klene, M.; Adamo, C.; Cammi, R.; Ochterski, J. W.; Martin, R. L.; Morokuma, K.; Farkas, O.; Foresman, J. B.; Fox, D. J. Gaussian16 Revision B.01. 2016.

(26) Frisch, M. J.; Trucks, G. W.; Schlegel, H. B.; Scuseria, G. E.; Robb, M. A.; Cheeseman, J. R.; Scalmani, G.; Barone, V.; Mennucci, B.; Petersson, G. A.; Nakatsuji, H.; Caricato, M.; Li, X.; P., H. H.; Izmaylov, A. F.; Bloino, J.; Zheng, G.; Sonnenb, D. J.; Hada, M.; Ehara, M.; Toyota, K.; Fukuda, R.; Hasegawa, J.; Ishida, M.; Nakajima, T.; Honda, Y.; Kitao, O.; Nakai, H.; Vreven, T.; Montgomery, J. A., J.; Peralta, J. E.; Ogliaro, F.; Bearpark, M.; Heyd, J. J.; Brothers, E.; Kudin, K. N.; Staroverov, V. N.; Kobayashi, R.; Normand, J.; Raghavachari, K.; Rendell, A.; Burant, J. C.; Iyengar, S. S.; Tomasi, J.; Cossi, M.; Rega, N.; Millam, J. M.; Klene, M.; Knox, J. E.; Cross, J. B.; Bakken, V.; Adamo, C.; Jaramillo, J.; Gomperts, R.; Stratmann, R. E.; Yazyev, O.; Austin, A. J.; Cammi, R.; Pomelli, C.; Ochterski, J. W.; Martin, R. L.; Morokuma, K.; Zakrzewski, V. G.; Voth, G. A.; Salvador, P.; Dannenberg, J. J.; Dapprich, S.; Daniels, A. D.; Farkas, O.; Foresman, J. B.; Ortiz, J. V.; Cioslowski, J.; Fox, D. J.; Gaussian 09, R. D. 0.; Frisch, M. J.; Trucks, G. W.; Schlegel, H. B.; Scuseria, G. E.; Robb, M. A.; Cheeseman, J. R.; Scalmani, G.; Barone, V.; Mennucci, B.; Petersson, G. A.; Nakatsuji, H.; Caricato, M.; Li, X.; P., H. H.; Izmaylov, A. F.; Bloino, J.; Zheng, G.; Sonnenb, D. J.; Hada, M.; Ehara, M.; Toyota, K.; Fukuda, R.; Hasegawa, J.; Ishida, M.; Nakajima, T.; Honda, Y.; Kitao, O.; Nakai, H.; Vreven, T.; Montgomery, J. A., J.; Peralta, J. E.; Ogliaro, F.; Bearpark, M.; Heyd, J. J.; Brothers, E.; Kudin, K. N.; Staroverov, V. N.; Kobayashi, R.; Normand, J.; Raghavachari, K.; Rendell, A.; Burant, J. C.; Iyengar, S. S.; Tomasi, J.; Cossi, M.; 
Rega, N.; Millam, J. M.; Klene, M.; Knox, J. E.; Cross, J. B.; Bakken, V.; Adamo, C.; Jaramillo, J.; Gomperts, R.; Stratmann, R. E.; Yazyev, O.; Austin, A. J.; Cammi, R.; Pomelli, C.; Ochterski, J. W.; Martin, R. L.; Morokuma, K.; Zakrzewski, V. G.; Voth, G. A.; Salvador, P.; Dannenberg, J. J.; Dapprich, S.; Daniels, A. D.; Farkas, O.; Foresman, J. B.; Ortiz, J. V.; Cioslowski, J.; Fox, D. J.; Gaussian, Inc., Wallingford CT, 2009. Gaussian 09, Revision D.01. Gaussian, Inc., Wallingford CT, 2009. 2009.

(27) Becke, A. D. Density-Functional Thermochemistry. IV. A New Dynamic Correlation Functional and Implications for Exact-Exchange Mixing. J. Chem. Phys. 1996, 104 (3), 1040-1046. https://doi.org/10.1063/1.470829.

(28) Lee, C.; Yang, W.; Parr, R. G. Development of the Colle-Salvetti Correlation-Energy Formula into a Functional of the Electron-Density. Phys. Rev. B 1988, 37 (2), 785-789. 10.1103/PhysRevB.37.785

(29) Zhao, Y.; Truhlar, D. G. The M06 Suite of Density Functionals for Main Group Thermochemistry, Thermochemical Kinetics, Noncovalent Interactions, Excited States, and Transition Elements: Two New Functionals and Systematic Testing of Four M06-Class Functionals and 12 Other Function. Theor. Chem. Acc. 2008, 120 (1-3), 215-241. https://doi.org/10.1007/s00214-007-0310-x.

(30) Kreienborg, N. M.; Merten, C. How to Treat C-F Stretching Vibrations? A Vibrational CD Study on Chiral Fluorinated Molecules. Phys. Chem. Chem. Phys. 2019, 21 (7), 3506-3511. https://doi.org/10.1039/c8cp02395f.

(31) Grimme, S.; Antony, J.; Ehrlich, S.; Krieg, H. A Consistent and Accurate Ab Initio Parametrization of Density Functional Dispersion Correction (DFT-D) for the 94 Elements HPu. J. Chem. Phys. 2010, 132 (15), 154104. https://doi.org/10.1063/1.3382344.

(32) Gordon, M. S.; Koob, R. D. An INDO Investigation of the Structure and Bonding of Acetylacetone and Trifluoroacetylacetone. J. Am. Chem. Soc. 1973, 95 (18), 5863-5867. https://doi.org/10.1021/ja00799a004.

(33) http://www.chemcraftprog.com.

(34) Ron, A.; Schnepp, O. Lattice Vibrations of the Solids N2, CO2, and CO. J. Chem. Phys. 1967, 46 (10), 3991-3998. https://doi.org/10.1063/1.1840475.

(35) Tayyari, S. F.; Milani-Nejad, F.; Rahemi, H. Structure and Vibrational Spectra of the Enol Form of Hexafluoro-Acetylacetone. A Density Functional Theoretical Study. Spectrochim. Acta - Part A Mol. Biomol. Spectrosc. 2002, 58 (8), 1669-1679. https://doi.org/10.1016/S13861425(01)00619-9.

(36) Nagashima, N.; Kudoh, S.; Nakata, M. Infrared and UV-Visible Absorption Spectra of Hexafluoroacetylacetone in a Low-Temperature Argon Matrix. I. Structure of a Non-Chelated Enol-Type Isomer. Chem. Phys. Lett. 2003, 374 (1-2), 59-66. https://doi.org/10.1016/S00092614(03)00688-2.

(37) Gutiérrez-Quintanilla, A.; Chevalier, M.; Platakyte, R.; Ceponkus, J.; Crépin, C. Selective Photoisomerisation of 2-Chloromalonaldehyde. J. Chem. Phys. 2019, 150 (3), 034305. https://doi.org/10.1063/1.5082916.

(38) Gutiérrez-Quintanilla, A.; Chevalier, M.; Platakyte, R.; Ceponkus, J.; Crépin, C. Open Enol Isomers of Trifluoroacetylacetone and Hexafluoroacetylacetone. Prep.

(39) Lozada-Garcia, R. R.; Ceponkus, J.; Chevalier, M.; Chin, W.; Mestdagh, J. M.; Crépin, C. Nuclear Spin Conversion to Probe the Methyl Rotation Effect on Hydrogen-Bond and Vibrational 
Dynamics. Angew. Chemie - Int. Ed. 2012, 51 (28), 6947-6950.

https://doi.org/10.1002/anie.201200727.

(40) Gutiérrez-Quintanilla, A.; Chevalier, M.; Ceponkus, J.; Lozada-García, R. R.; Mestdagh, J. M.; Crépin, C. Large Amplitude Motions within Molecules Trapped in Solid Parahydrogen. Faraday Discuss. 2018, 212, 499-515. https://doi.org/10.1039/c8fd00080h.

(41) Note: observed by us in 2-chloromalonaldehyde (A. Gutierrez-Quintanilla et al. Phys.Chem.Chem.Phys.,20, 12888-12897 (2018) and ref. 37) and in other $\beta$-dicarbonyles, ${ }^{24}$ as well as by other authors, e.g. S. Yusuf et al. Spectrochimica Acta Part A, 128, 46-53 (2014). 
TOC Image

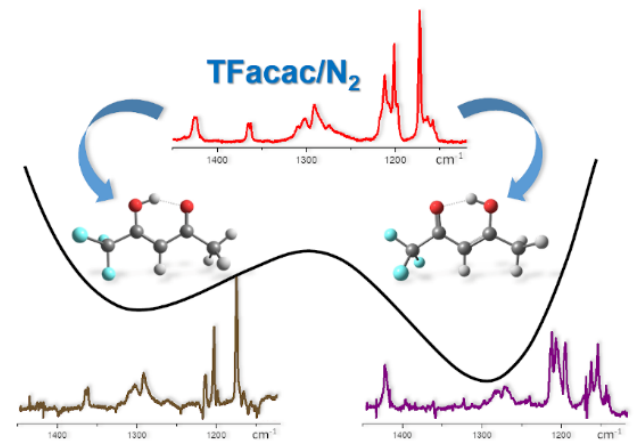

